\section{Successful Desensitization to Irinotecan After Severe Hypersensitivity Reaction}

Cubero JL ${ }^{1,2}$, Escudero $\mathrm{P}^{2,3}$, Yubero $\mathrm{A}^{2,3}$, Millán $\mathrm{P}^{4}$, Sagredo $\mathrm{MA}^{5}$, Colás $\mathrm{C}^{1,2}$

${ }^{1}$ Allergy Department, University Hospital Lozano Blesa of Zaragoza, Zaragoza, Spain

${ }^{2}$ Instituto de Investigación Sanitaria Aragón (IIS Aragón), Spain

${ }^{3}$ Oncology Department, University Hospital Lozano Blesa of Zaragoza, Zaragoza, Spain

${ }^{4}$ Intensive Care Unit, University Hospital Lozano Blesa of Zaragoza, Zaragoza, Spain

${ }^{5}$ Pharmacy Department, University Hospital Lozano Blesa of Zaragoza, Zaragoza, Spain

J Investig Allergol Clin Immunol 2016; Vol. 26(5): 314-316 doi: 10.18176/jiaci.0075

Key words: Desensitization. Hypersensitivity reactions. Irinotecan.

Palabras clave: Desensibilización. Reacciones de hipersensibilidad. Irinotecan.

Irinotecan is an antineoplastic drug that is widely used to treat gastrointestinal malignancies. It prevents DNA from unwinding by inhibition of topoisomerase I [1]. Hypersensitivity reactions (HSRs), which can occur with most drugs, are unpredictable, can affect any organ or system, and range widely in clinical severity from mild pruritus to anaphylaxis. In most cases, the culprit drug is avoided in the future, but for certain patients, the particular drug may be essential for optimal therapy. Under these circumstances, desensitization to the drug in question is a viable option. This approach induces a temporary state of tolerance to the drug responsible for a proven HSR [2].

A 57-year-old man with a personal history of dyslipidemia, high blood pressure, and hyperuricemia and no history of allergy was diagnosed in June 2014 with a low rectal neoplasm $7 \mathrm{~cm}$ from the anal margin with synchronous liver metastases (T3N2M1). Short-course radiotherapy was administered, followed by laparoscopic ultralow anterior resection with manual colorectal anastomosis and removal of a surgical specimen through the anus (pass-through) with protective lateral ileostomy.

Postoperative evaluation revealed that the liver tumors had progressed and were nonresectable; consequently, chemotherapy was initiated with CAPOX (capecitabine and oxaliplatin) in combination with bevacizumab (the patient harbored a KRAS mutation), and by April 2015, the patient had received 6 cycles.
The response of the liver metastases to chemotherapy was poor, so it was decided to administer 4 cycles of irinotecanloaded drug-eluting beads (DEBIRI, BTG) via intra-arterial infusion. The patient received $100 \mathrm{mg}$ of irinotecan in DC Bead (an embolic drug-eluting bead for controlled loading and release of chemotherapeutic agents) (BTG) of 100$300 \mu \mathrm{m}$ between May and September 2015 and showed no hypersensitivity symptoms.

Owing to disease progression (enlargement of the liver nodules and emergence of new liver foci and pulmonary nodules), treatment was initiated 2 months later with aflibercept in combination with FOLFIRI (irinotecan, calcium levofolinate, and 46-hour 5-fluorouracil in a continuous infusion). In the first cycle, during the administration of irinotecan alone, the patient presented lingual angioedema, generalized urticaria, desaturation, and blurred vision that lasted 6 hours and required various doses of corticosteroids, systemic antihistamines, and oxygen. Given the severity of the reaction, calcium levofolinate and 5-fluorouracil were discontinued. Before the diagnosis of allergy to irinotecan, the patient had received aflibercept, calcium levofolinate, and 5-fluorouracil without symptoms.

The patient was assessed in the allergy department, where skin tests with irinotecan were performed at the concentrations described by Alvarez-Cuesta et al [3]: prick test, $20 \mathrm{mg} / \mathrm{mL}$; and intradermal tests, $2 \mathrm{mg} / \mathrm{mL}$ and $20 \mathrm{mg} / \mathrm{mL}$. The result was positive with the $20-\mathrm{mg} / \mathrm{mL}$ intradermal test. Drugs for prick and intradermal tests were prepared by the cytotoxic unit of the pharmacy department.

Drug desensitization was programmed using a 12-step protocol adapted from Castells et al [4], which enabled a cumulative dose of $336.4 \mathrm{mg}$ of irinotecan to be administered (Table). Pretreatment was with oral acetylsalicylic acid $500 \mathrm{mg}$ (instead of $325 \mathrm{mg}$, because of commercial availability) and oral montelukast $10 \mathrm{mg}$ at 48 hours and 24 hours before and on the day of desensitization. The other drugs in the patient's protocol (aflibercept $296 \mathrm{mg}$, fosaprepitant $150 \mathrm{mg}$, dexamethasone $12 \mathrm{mg}$, ondansetron $8 \mathrm{mg}$, atropine $0.5 \mathrm{mg}$, calcium levofolinate $373.8 \mathrm{mg}$, and 5 -fluorouracil $4486 \mathrm{mg}$ ) were administered following the order, dose, and rate of the oncology department's routine administration protocol. Solutions were prepared by the cytotoxic unit and then administered at the bedside by a specialized nurse from the allergy department. An allergologist experienced in desensitization was present throughout the infusion in the outpatient center.

Desensitization was successful and the patient did not experience a reaction during the infusion or during the following hours. Subsequent cycles were scheduled according to the original desensitization protocol.

We report a successful and rapid protocol for desensitization to irinotecan in a patient who became sensitized to it during 
Table. Irinotecan Desensitization Protocol

\begin{tabular}{|c|c|c|c|c|c|c|}
\hline & \multicolumn{2}{|c|}{ Solution Volume } & \multicolumn{2}{|l|}{ Solution Concentration } & Total Dose in Each Solution & \\
\hline Solution A & $500.17 \mathrm{~mL}$ & & $0.007 \mathrm{mg} / \mathrm{mL}$ & $3.4 \mathrm{~m}$ & & \\
\hline Solution B & $501.68 \mathrm{~mL}$ & & $0.067 \mathrm{mg} / \mathrm{mL}$ & 33.6 & & \\
\hline Solution C & $516.67 \mathrm{~mL}$ & & $0.645 \mathrm{mg} / \mathrm{mL}$ & 333.4 & & \\
\hline Step & Solution & Rate, $\mathrm{mL} / \mathrm{h}$ & Time, Min & $\begin{array}{l}\text { Volume } \\
\text { Administered, } \\
\mathrm{mL}\end{array}$ & $\begin{array}{l}\text { Dose } \\
\text { Administered, } \\
\text { mg }\end{array}$ & $\begin{array}{l}\text { Cumulative } \\
\text { Dose } \\
\text { Infused, mg }\end{array}$ \\
\hline 1 & A & 6 & 15 & 1.50 & 0.010 & 0.010 \\
\hline 2 & $\mathrm{~A}$ & 11 & 15 & 2.75 & 0.019 & 0.029 \\
\hline 3 & A & 23 & 15 & 5.75 & 0.039 & 0.068 \\
\hline 4 & A & 45 & 15 & 11.25 & 0.076 & 0.144 \\
\hline 5 & $\mathrm{~B}$ & 11 & 15 & 2.75 & 0.184 & 0.329 \\
\hline 6 & $\mathrm{~B}$ & 23 & 15 & 5.75 & 0.385 & 0.714 \\
\hline 7 & B & 45 & 15 & 11.25 & 0.753 & 1.467 \\
\hline 8 & $\mathrm{~B}$ & 90 & 15 & 22.50 & 1.507 & 2.974 \\
\hline 9 & $\mathrm{C}$ & 23 & 15 & 5.75 & 3.710 & 6.684 \\
\hline 10 & $\mathrm{C}$ & 45 & 15 & 11.25 & 7.259 & 13.944 \\
\hline 11 & $\mathrm{C}$ & 90 & 15 & 22.50 & 14.519 & 28.463 \\
\hline 12 & $\mathrm{C}$ & 180 & 159.1 & 477.17 & 307.937 & 336.400 \\
\hline
\end{tabular}

Volume of each solution administered: solution A,21.25 mL;solution B, $42.25 \mathrm{~mL}$; and solution C, $516.67 \mathrm{~mL}$.

Solutions were prepared in the cytotoxicity unit of the pharmacy department. The tubing of each bag is primed with the antineoplastic drug in the pharmacy and connected to a running saline line in close proximity to the patient, thus enabling delivery of small volumes during the initial steps of the desensitization protocol.

The protocol was adapted from Castells et al [4]. Irinotecan is always diluted in $500 \mathrm{~mL}$ in our hospital, instead of $250 \mathrm{~mL}$, as per the original protocol, and the infusion rate is adapted to that change. No diluent is removed when a solution is prepared owing to our local safety requirements: the amounts added are $0.17 \mathrm{~mL}$ of $20 \mathrm{mg} / \mathrm{mL}$ irinotecan (commercial concentration, total volume, $500.17 \mathrm{~mL}$ ) in solution A, $1.68 \mathrm{~mL}$ (total volume, $501.68 \mathrm{~mL}$ ) in solution $\mathrm{B}$, and $16.67 \mathrm{~mL}$ (total volume, $516.67 \mathrm{~mL}$ ) in solution C.

intra-arterial chemoembolization of liver metastases. The patient experienced a severe HSR to during the first intravenous dose of irinotecan, which was administered 2 months after the last chemoembolization session. We found only 1 other recent case report of desensitization to the drug, although the protocol used differed from ours, especially in terms of premedication [5]: the regimen administered the night before admission comprised intravenous dexamethasone 12 $\mathrm{mg}$, oral fexofenadine $180 \mathrm{mg}$, and oral cimetidine $400 \mathrm{mg}$; the regimen administered 2 hours before the procedure comprised intravenous dexamethasone $20 \mathrm{mg}$, oral promethazine $50 \mathrm{mg}$, oral fexofenadine $180 \mathrm{mg}$, and intravenous ranitidine $50 \mathrm{mg}$.

HSRs are unpredictable, can affect any organ or system, and range widely in clinical severity from mild pruritus to anaphylaxis. In the field of oncology, they have been described with many drugs, and their frequency has been reported to be 5\%-27\% for platins, $10 \%-30 \%$ for taxanes, and $0.6 \%-10 \%$ for specific monoclonal antibodies [6]. In the study of AlvarezCuesta et al [3], irinotecan was the suspected culprit drug in 11 of the 186 patients $(5.9 \%)$ referred for desensitization over a 3 -year period (data confirmed HSR to irinotecan, although the characteristics of the reactions are not provided in the article).

Drug desensitization induces a temporary state of tolerance to the drug responsible for a specific HSR [2]. The 12-step protocol (3 bags) described by Castells et al [6] is the most frequently used, although other protocols should be considered in patients with severe HSRs and anaphylactic reactions [6]. Pretreatment was with oral acetylsalicylic acid $500 \mathrm{mg}$ and oral montelukast $10 \mathrm{mg}$ at 48 hours and 24 hours before and on the day of desensitization. In our department, we use systematic premedication with acetylsalicylic acid and montelukast to improve tolerability of the desensitization protocol $[6,7]$. We do not use systematic premedication with antihistamines or corticosteroids; these drugs are only used in patients who develop repeated reactions during previous desensitization protocols.

In conclusion, rapid desensitization is a promising method for the delivery of antineoplastic drugs, monoclonal 
antibodies, antibiotics, and other drugs after HSRs and should be considered when no acceptable therapeutic alternatives are available.

\section{Funding}

The authors declare that no funding was received for the present study.

\section{Conflicts of Interest}

The authors declare that they have no conflicts of interest.

\section{References}

1. Pommier Y. Drugging topoisomerases: lessons and challenges. ACS Chem Biol. 2013;8(1):82-95.

2. Cernadas JR, Brockow K, Romano A, Aberer W, Torres MJ, Bircher A, Campi P, Sanz ML, Castells M, Demoly P, Pichler WJ; European Network of Drug Allergy and The EAACl interest group on drug hypersensitivity. General considerations on rapid desensitization for drug hypersensitivity - a consensus statement. Allergy. 2010;65(11):1357-66

3. Alvarez-Cuesta $E$, Madrigal-Burgaleta $R$, Angel-Pereira $D$, Ureña-Tavera A, Zamora-Verduga M, Lopez-Gonzalez P, BergesGimeno MP. Delving into cornerstones of hypersensitivity to antineoplastic and biological agents: value of diagnostic tools prior to desensitization. Allergy. 2015;70(7):784-94.

4. Castells MC, Tennant NM, Sloane DE, Hsu Fl, Barrett NA Hong DI, Laidlaw TM, Legere HJ, Nallamshetty SN, Palis RI, Rao JJ, Berlin ST, Campos SM, Matulonis UA. Hypersensitivity reactions to chemotherapy: outcomes and safety of rapid desensitization in 413 cases. J Allergy Clinlmmunol. 2008;122(3):574-80

5. Abu-Amna M, Hassoun G, Hadad S, Haim N, Bar-Sela G. Successful Desensitization Protocol for Hypersensitivity Reaction Caused by Irinotecan in a Patient With Metastatic Colorectal Cancer. Clin Colorectal Cancer. 2015;14(4):e4951.

6. Castells Guitart MC. Rapid drug desensitization for hypersensitivity reactions to chemotherapy and monoclonal antibodies in the 21 st century. J Investig Allergol Clin Immunol. 2014;24(2):72-9.

7. Breslow RG, Caiado J, Castells MC. Acetylsalicylic acid and montelukast block mast cell mediator-related symptoms during rapid desensitization. Ann Allergy Asthma Immunol. 2009;102(2):155-60

Manuscript received February 12, 2016; accepted for publication May 9, 2016

José Luis Cubero Saldaña

Servicio de Alergia

Hospital Clínico Universitario Lozano Blesa Avda. San Juan Bosco 15. 50.009 - Zaragoza

E-mail: jlcubero@salud.aragon.es

\section{Hypersensitivity to Quail Egg Proteins: What About Hen Egg?}

Micozzi $\mathrm{S}^{1,2}$, Bartolomé $\mathrm{B}^{3}$, Sanchís-Merino $\mathrm{ME}^{4}$, Alfaya $\mathrm{T}^{5}$, Aldunate $\mathrm{T}^{6}$, Diaz $\mathrm{M}^{7}$, Pastor-Vargas $\mathrm{C}^{8}$

${ }^{1}$ University General Hospital Gregorio Marañón, Madrid, Spain ${ }^{2}$ Gregorio Marañón Health Research Institute, Madrid, Spain

${ }^{3} R \& D$ Department Bial-Aristegui, Bilbao, Spain

${ }^{4}$ University Hospital Río Hortega, Valladolid, Spain

${ }^{5}$ University General Hospital of Ciudad Real, Ciudad Real, Spain

${ }^{6}$ Hospital Reina Sofia of Tudela, Navarra, Spain

${ }^{7}$ University and Polytechnic Hospital La Fe, Valencia, Spain

${ }^{8}$ Immunology Department, IIS-Fundación Jiménez Díaz, Madrid, Spain

J Investig Allergol Clin Immunol 2016; Vol. 26(5): 316-318 doi: $10.18176 /$ jiaci.0076

Key words: Egg allergy. Hen egg. Quail egg.

Palabras clave: Alergia a huevo. Huevo de gallina. Huevo de codorniz.

Food allergy is a major problem in society today. Since it is consumed throughout the world, hen's egg (HE) is the most common type of egg allergy.

The main HE allergens are proteins from the white, namely, ovalbumin $\left(\mathrm{Gal} \mathrm{d} 2\left[\mathrm{OVA}_{\mathrm{h}}\right]\right)$, ovotransferrin $\left(\mathrm{Gal} \mathrm{d} 3\left[\mathrm{OVT}_{\mathrm{h}}\right]\right)$, lysozyme (Gal d 4 [LYS $]$ ]), and ovomucoid (Gal d 1 [OVM $\left.\mathrm{OV}_{\mathrm{h}}\right]$ ).

Allergy to egg from other species, especially quail's egg (QE), in patients who tolerate HE is much less frequent, although some cases have been reported [1-3].

The objectives of the present study were to identify the causative allergen in a group of patients with hypersensitivity to QE who tolerate $\mathrm{HE}$ and to describe the pattern of hypersensitivity to HE in this group.

We studied 5 patients ( 4 females and 1 male), with a mean age of 25 years (range, 10-36 years). Symptoms induced by undercooked QE (inclusion criteria) included angioedema (1 patient) and anaphylaxis (4 patients). All patients were atopic. Prior to the anaphylactic reaction, all patients had tolerated QE and HE (at different degrees of cooking), as well as chicken, turkey, and quail meat. After the reaction, all 5 patients tolerated cooked and undercooked HE, and 4 patients tolerated quail, turkey, and chicken meat. The remaining patient has not eaten quail meat since then, but he tolerates turkey and chicken meat.

Informed consent was obtained in all cases. The study was approved by the local ethics committee.

Skin prick-by-prick tests (SPPT) were performed with cooked and uncooked yolk and white from QE. Skin prick tests (SPT) were performed with commercial extracts of common inhalant allergens, $\mathrm{OVA}_{\mathrm{h}}, \mathrm{OVM}_{\mathrm{h}}, \mathrm{OVT}_{\mathrm{h}}, \mathrm{LYS}_{\mathrm{h}}$, and HE yolk and white (Bial-Aristegui, Leti, and ALK-Abelló). The results of the tests are shown in the Table.

Serum total and specific IgE levels against yolk and white from $\mathrm{HE}$ and against Gal d 1, 2, and 3 were measured using 


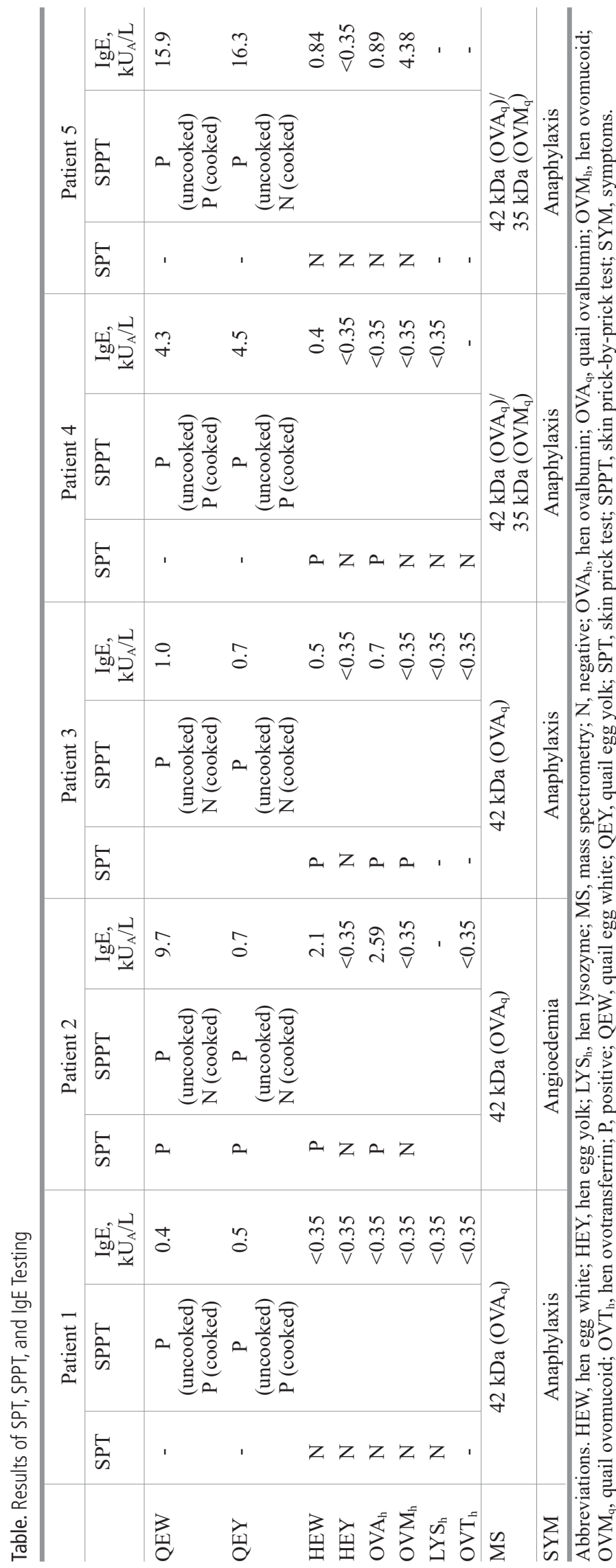

ImmunoCAP (Thermo Fisher Scientific) according to the manufacturer's instructions. Specific IgE from QE white and yolk was determined using EAST; the solid phase was obtained by coupling the extract solution $(10 \mathrm{mg} / \mathrm{mL})$ to 6-mm cyanogen bromide-activated paper discs, as described by Ceska and Lunqvist [4]. The results were expressed in accordance with the manufacturer's instructions for the CAP assay (HYTEC Specific IgE EIA kit) and EAST (HYCOR Biomedical Ltd). Values $\geq 0.1$ and $\geq 0.35 \mathrm{kU}_{\mathrm{A}} / \mathrm{L}$ were considered positive for EAST and CAP, respectively (Table).

QE white and yolk extracts were analyzed using SDSPAGE, and immunoblotting was performed using the patient's serum, which was incubated overnight and revealed with a second antibody antihuman IgE, as previously described [5].

The result of IgE-immunoblotting with QE white and yolk extracts showed the same IgE-binding profile, although this was much more intense in white than in yolk (data not shown). Two main IgE binding bands were detected: a 42-kDa band, which was revealed in all the assayed sera, and a $35-\mathrm{kDa}$ band, which was detected in 2 sera. In addition, a band of about $97 \mathrm{kDa}$ was detected in patients 3 and 4 .

Proteins were identified at the Proteomics Department of the Universidad Complutense de Madrid, a member of the ProteoRed Network.

The 42-kDa and 35-kDa IgE-binding bands were identified and proved to be ovalbumin and ovomucoid from $\mathrm{QE}\left(\mathrm{OVA}_{\mathrm{q}}, \mathrm{OVM}_{\mathrm{q}}\right)$, respectively. The molecular weight of $\mathrm{OVM}_{\mathrm{h}}$ is about $30 \mathrm{kDa}$; that of OVMq in a standard $12.5 \%$ SDS-PAGE electrophoresis gel is slightly higher [6].

The $97-\mathrm{kDa}$ binding protein was identified as ovotransferrin.

We present 5 cases of hypersensitivity to QE in patients who tolerated HE. As reported by other authors [7], the proteins from different types of egg whites can present crossreactivity, especially if their phylogenetic homology is high. Since both quail and hen belong to the Galliforme order, their proteins present high homology. In fact, although all patients tolerated cooked and uncooked HE, 3 of the 5 patients were sensitized to $\mathrm{OVA}_{\mathrm{h}}$ (most likely by cross-reaction), as deduced from positive SPT and specific IgE results.

All the patients' sera had specific IgE against $\mathrm{OVA}_{\mathrm{q}}$ (heatsensitive), thus explaining why the allergic reaction occurred with undercooked QE (fried, omelette) in all patients. In addition, sera from patients 4 and 5 revealed $\mathrm{OVM}_{\mathrm{q}}$ in the immunoblotting assay; the SPPT result to cooked QE white was also positive. In patient 1 , the SPPT was performed with QE omelette, whose cooked level is difficult to establish; consequently, the positive SPPT result to QE white, despite being caused by $\mathrm{OVM}_{\mathrm{q}}$, was not observed. Patients whose serum did not reveal $\mathrm{OVM}_{\mathrm{q}}$ did not manifest milder reactions than the others.

Only 1 patient had a positive SPT result with $\mathrm{OVM}_{\mathrm{h}}$, and 1 had positive IgE against $\mathrm{OVM}_{\mathrm{h}}$, possibly because of crossreactive carbohydrate-determining reagents.

Other discrepancies between SPT and ImmunoCAP are probably linked to the difficulties associated with extract standardization: $\mathrm{OVM}_{\mathrm{h}}$ in SPT extracts is not as purified as in those used for ImmunoCAP.

All the patients had a positive SPPT result to QE yolk, although no major QE yolk proteins were revealed in the QE 
immunoblotting assay. In addition, after the allergic reaction, all patients tolerated poultry meat, indicating that $\alpha$-livetin (quail albumin) was not involved in any of these cases.

The difficulty in obtaining a QE yolk sample without QE white contamination, as reported elsewhere [7], could explain the positive results for QE yolk in the SPPT and immunoblotting assay.

Although allergy to QE - with or without HE sensitivityhas been reported $[2,3,8,9]$, ours is the first case series in which the causative proteins were identified.

We found only 1 case of non-IgE-mediated food hypersensitivity reaction to QE [10].

In conclusion, in the 5 patients we report, the main QE allergen is ovalbumin. Although proteins from $\mathrm{HE}$ and $\mathrm{QE}$ showed cross-reactivity, patients commonly tolerate $\mathrm{HE}$ consumption even when they have QE allergy. Since patients with QE allergy can show different HE skin test results (positive SPT and/or SSPT and/or specific IgE to HE proteins, with good tolerance to $\mathrm{HE}$ ), these results should not be used to predict intolerance to $\mathrm{HE}$.

\section{Funding}

The authors declare that no funding was received for the present study.

\section{Conflicts of Interest}

The authors declare that they have no conflicts of interest.

\section{References}

1. Añíbarro B, Seoane FJ, Vila C, Lombardero M. Allergy to eggs from duck and goose without sensitization to hen egg proteins. J Allergy Clin Immunol. 2000;105(4):834-6.

2. Fernández Cortés $S$, Fernández García A, Armentia Medina A, Pineda F. Duck egg allergy in a patient who tolerates hen's eggs. J Investig Allergol Clin Immunol. 2013;23(2):135-6.

3. Caro Contreras FJ, Giner Muñoz MT, Martin Mateos MA, Plaza Martin AM, Sierra Martinez Jl, Lombardero M. Allergy to quail's egg without allergy to chicken's egg. case report. Allergol Immunopathol (Madr). 2008;36(4):234-7.

4. Ceska M, Lunqvist U. A new and simple radioimmunoassay method for the determination of $\mathrm{lgE}$. Immunochemistry. 1972;9:102-5.

5. Muñoz-García E, Luengo-Sánchez O, Haroun-Díaz E, Maroto AS, Palacín A, Díaz-Perales $A$, de Las Heras Gozalo $M$, Labrador-Horrillo M, Vivanco F, Cuesta-Herranz J, PastorVargas C. Identification of thaumatin-like protein and aspartyl protease as new major allergens in lettuce (Lactuca sativa). Mol Nutr Food Res. 2013;57(12):2245-52.

6. Hjelmeland LM, Chrambach A. Electrophoresis and electrofocusing in detergent containing media: a discussion of basic concepts. Electrophoresis. 1981;2:1-11.

7. Langeland T. A clinical and immunological study of allergy to hen's egg white. I. A clinical study of egg allergy. Clin Allergy. 1983;13(4):371-82

8. Alessandri C, Calvani M Jr, Rosengart L, Madella C. Anaphylaxis to quail egg. Allergy. 2005;60(1):128-9.
9. Escribano MM, Serrano $P$, Muñoz-Bellido FJ, de la Calle $A$, Conde J. Oral allergy syndrome to bird meat associated with egg intolerance. Allergy. 1998 Sep;53(9):903-4.

10. Sanlidag B, Babayigit Hocaoglu A, Bahceciler N. Quail's EggInduced Severe Enterocolitis in a Child Tolerant to Hen's Egg: First Reported Case. J Investig Allergol Clin Immunol. 2016;26(2):118-9. Manuscript received February 19, 2016; accepted for publication
May 10, 2016.

Sarah Micozzi

Hospital General Universitario Gregorio Marañón

C/ Doctor Esquerdo, 46 28007 Madrid, Spain E-mail: sarah.micozzi@gmail.com 


\section{Is Vitamin D Deficiency a Marker of Severity of Wheezing in Children? A Cross-sectional Study}

\author{
Urrutia-Pereira $\mathrm{M}^{1}$, Solé $\mathrm{D}^{2}$
}

${ }^{1}$ Faculty of Medicine, Federal University of Pampas and Pediatric Program for the Prevention of Asthma (PIPA) - City Hall of Uruguayana, Rio Grande do Sul, Brazil

${ }^{2}$ Division of Allergy, Clinical immunology and Rheumatology, Department of Pediatrics, Federal University of São Paulo-Escola Paulista de Medicina, São Paulo, São Paulo, Brazil

J Investig Allergol Clin Immunol 2016; Vol. 26(5): 319-321 doi: $10.18176 /$ jiaci.0077

Key words: Vitamin D. Children. Wheezing. Asthma. Immunoglobulin E. Palabras clave: Vitamina D. Niños. Sibilancias. Asma. Inmunoglobulina E.

Wheezing is a common complaint in pediatric emergency departments, especially in developing countries [1]. The relationship between wheezing in childhood and subsequent development of asthma remains unclear. Individual genetic and immunological factors, environmental factors, lifestyle, dietary habits, and deficiencies of vitamins such as vitamin D (VitD) have been associated with the development of wheezing/asthma [2].

The association between serum VitD levels and various diseases, including asthma, has been extensively studied. However, the results for asthma are controversial [3].

We studied the relationship between serum VitD levels and wheezing in children treated at the Pediatric Program for the Prevention of Asthma (PIPA), Uruguayana, Brazil [4].

All children (3-47 months; $n=370$ ) with occasional wheezing (OW; up to 2 episodes of wheezing in the previous year, $\mathrm{n}=115$ ) and recurrent wheezing ( $\mathrm{RW} ; \geq 3$ wheezing episodes in the previous year, $\mathrm{n}=255$ ) referred to PIPA (from March 2012 to March 2013; outpatients) were enrolled in this cross-sectional study. Children with other chronic diseases, genetic syndromes, and/or birth defects were not included. At admission, the patient's parents and/or guardians completed a standardized written questionnaire (International Study of Wheezing in Infants; EISL) consisting of 45 questions about demographic characteristics, wheezing and risk factors, as well as the severity of wheezing [5]. RW patients were classified according to the number of episodes in the previous year as having had up to 6 episodes/year $(\mathrm{n}=150)$ or $>6$ episodes/ year $(\mathrm{n}=105)$.

Peripheral blood samples were obtained from all patients for determination of total serum IgE using ImmunoCap (Thermo Scientific) and VitD levels using electrochemiluminescence. Patients were classified according to VitD level as having deficiency $(<20 \mathrm{ng} / \mathrm{mL}[<50 \mathrm{nmol} / \mathrm{L}])$, insufficiency $(21-$ $29 \mathrm{ng} / \mathrm{mL}[52.5-72.5 \mathrm{nmol} / \mathrm{L}])$, and sufficiency $(\geq 30 \mathrm{ng} / \mathrm{mL}$ [75 nmol/L]) [2].

In the initial statistical analysis, OW was compared with $\mathrm{RW}$, and patients with $<6$ episodes/year were compared with those with $\geq 6$ episodes/year (Table). Categorical variables (gender, visits to the emergency department, use of oral corticosteroids, severe wheezing, hospitalizations due to wheezing, hospitalizations due to pneumonia, and physiciandiagnosed asthma) were analyzed using the chi-square or Fisher exact test. Continuous variables (age, weight, height, age at first episode, number of colds and age at first cold, serum VitD levels, total serum IgE levels) were analyzed using the $t$ test (normal distribution) or Mann-Whitney test (nonnormal distribution). All analyses were performed with SPSS 18.0 (SPSS Inc), and statistical significance was set at $P<.05$. The study was approved by the local ethics committee, and all parents and/or guardians signed the informed consent.

The Table shows the main characteristics of the patients enrolled in the study. Both groups (OW and RW) were similar in gender, age, and current weight and height. None of the patients were receiving VitD supplements during the month before entering PIPA. RW children were younger at the first episode of wheezing and of upper respiratory tract infection, used oral corticosteroids more frequently than OW patients, and had a higher frequency of upper respiratory tract infection, nighttime awakenings, and hospitalization for wheezing or pneumonia.

These data are consistent with those previously observed in the EISL study [5], in which the analysis of risk factors associated with RW revealed that having a cold during the first 3 months of life indicated a 3-fold higher risk of RW [6]. Viral respiratory infections are considered a major cause of wheezing, particularly when they are recurrent. As observed in the patients we report, early onset of wheezing coincided with the first episode of viral respiratory infection, in addition to being an associated factor for the subsequent development of asthma [6]. A medical diagnosis of asthma was more frequent in RW patients, especially those with $>6$ episodes of wheezing in the previous year, than in OW patients.

The role of VitD in respiratory antiviral defense has been evaluated in several studies, with conflicting results. In our study, we observed significantly higher serum VitD levels in RW children, especially those with more severe forms, than in OW children and children with milder conditions. Although obvious, these results do not allow us to draw more conclusive findings about the relationship between VitD and wheezing/ asthma for the patients in the present study owing to limitations affecting our study, namely, its retrospective design, lack of control with respect to breastfeeding, individual family atopic status, and time of and age at collection of blood samples. Therefore, we were unable to determine the causal connection between VitD and the development of wheezing and/or asthma. In addition, we provide no information about the mother's prenatal VitD levels or on VitD supplements before or during pregnancy. Likewise, we provide no information on the influence of confounders related to maternal diet, socioeconomic factors, lifestyle, or epigenetic changes caused by the environment to which the mothers were exposed [7].

It is important to stress that for a given population, the many factors that can modify the effect of variations in VitD concentrations in children include season, sun exposure, socioeconomic status, ethnicity, age, gender, dietary habits, interaction with other vitamins and trace elements, prenatal 


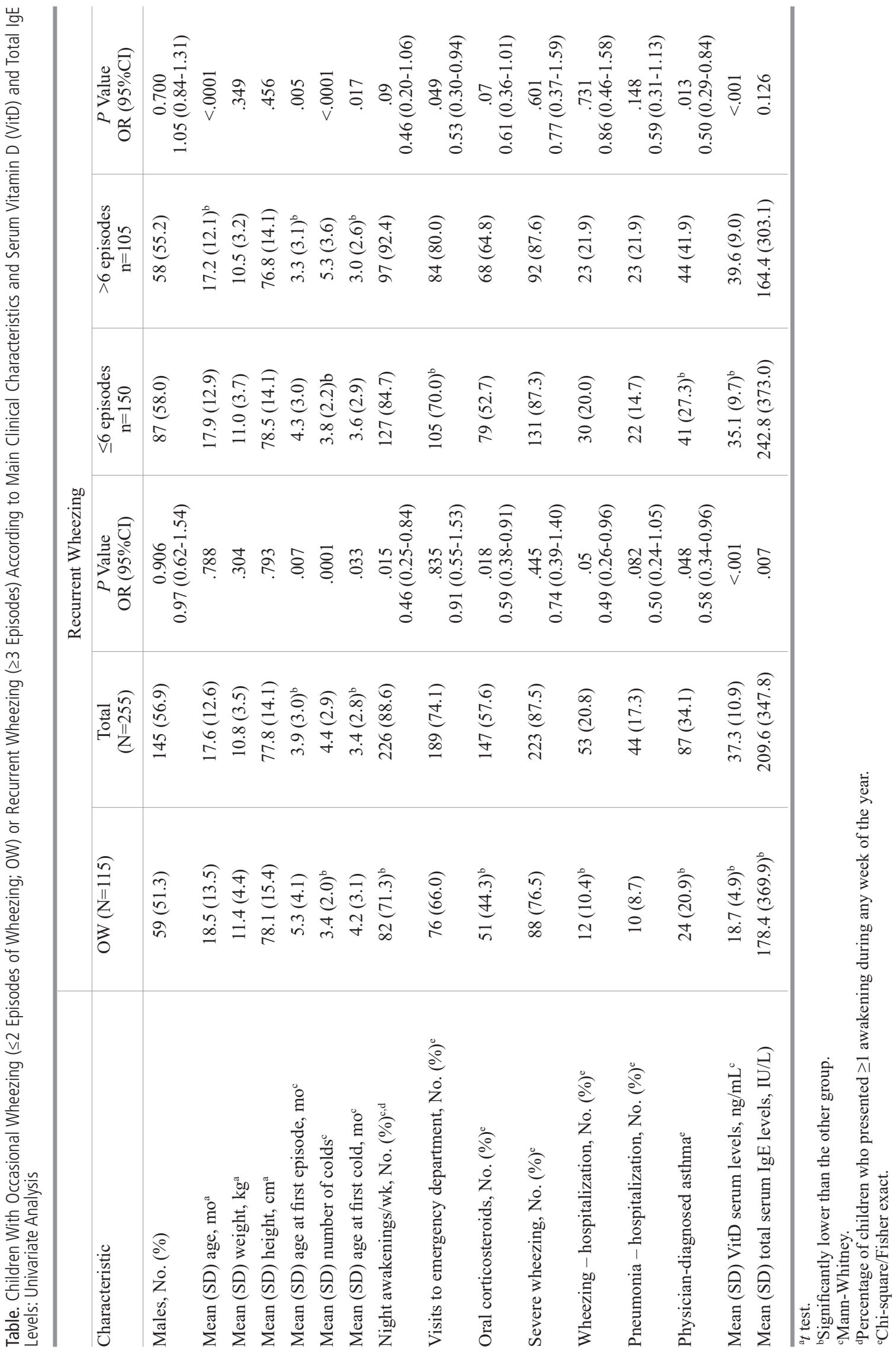


and postnatal tobacco exposure, type of delivery, maternal educational level, exposure to paracetamol, and viral infections during the first year of life [8].

Although many studies have focused on the relationship between high serum VitD levels and reduced risk of asthma exacerbations, evidence of an association with the incidence, prevalence, or severity of asthma is scarce.

We observed higher levels of total IgE among RW children, although these were not associated with the frequency of episodes, and found that they were parallel to serum VitD levels. However, high levels of serum IgE were recently reported to be a risk factor for severe asthma in a report stressing the relationship between serum levels of VitD, IgE, and inflammatory T cytokines [10]. The authors postulated that the relationship was U-shaped, ie, both high and low serum VitD levels of were associated with high levels of IgE and a similar immune response [10]. This relationship may explain our findings.

In conclusion, we observed earlier onset and higher severity of wheezing among RW children followed at PIPA than among OW children. We also observed high levels of VitD and total serum IgE. Further cohort studies are necessary to establish a cause-effect relationship.

\section{Funding}

The authors declare that no funding was received for the present study.

\section{Conflicts of Interest}

The authors declare that they have no conflicts of interest.
6. Garcia-Marcos L, Mallol J, Solé D, Brand P; EISL Study Group. International study of wheezing in infants: risk factors in affluent and non-affluent countries during the first year of life. Pediatr Allergy Immunol. 2010;21:878-88.

7. Martineu AR. Curiouser and curiouser: the role of vitamin $D$ in the prevention of acute respiratory infection. Acta Paediatrica. 2015;104:331-3.

8. Koistinen $A$, Turunen $R$, Vuorinen $T$, Söderlund-Venermo $M$, Camargo CA Jr, Ruuskanen O, Jartti T. Vitamin D, virus etiology, and atopy in first-time wheezing children in Finland. Pediatric Allergy Immunol. 2014;25:834-7.

9. Kull I, Bergstrom A, Melen E, Lilja G, van Hage M, Pershagen G, Wickman M. Early-life supplementation of vitamins A and $D$, in water-soluble form or in peanut oil, and allergic diseases during childhood. J Allergy Clin Immunol. 2006;118:1299304.

10. Pfeffer PE, Mann EH, Hornsby E, Chambers ES, Chen Y-H, Rice L, Hawrylowicz. Vitamin D influences asthmatic pathology through its action on diverse immunological pathways. Ann Am Thorac Soc. 2014:11(S5):S314-S21.

Manuscript received October 20, 2015; accepted for publication May 11, 2016

Dirceu Solé

Rua dos Otonis 725

04025-002, Vila Mariana, São Paulo

Brazil

E-mail: dirceu.sole@unifesp.br

\section{References}

1. Castro-Rodriguez JA, Garcia-Marcos L. Wheezing and asthma in childhood: an epidemiology approach. Allergol Immunopathol (Madr). 2008;36:280-90.

2. Saggese $G$, Vierucci $F$, Boot AM, Czech-Kowalska J, Weber G, Camargo CA Jr, Mallet E, Fanos M, Shaw NJ, Holick MF. Vitamin D in childhood and adolescent: an expert position statement. Eur J Pediatr. 2015;174:565-76.

3. Gergen PJ, Teach SJ, Mitchell HE, Freishtat RF, Calatroni A, Matsui E, Kattan M, Bloomberg GR, Liu AH, Kercsmar C, O'Connor G, Pongracic J, Rivera-Sanchez Y, Morgan WJ, Sorkness CA, Binkley N, Busse W. Lack of a relation between serum 25-hydroxyvitamin D concentrations and asthma in adolescents. Am J Clin Nutr. 2013;97:1228-34.

4. Urrutia-Pereira M, Avila JBG, Solé D. Childhood Asthma Prevention Program (PIPA): The purpose of a specialized care program for children with wheezing/asthma. J Bras Pneumol. 2015;41(5):1-6 ahead of print at - http://dx.doi.org/10.1590/ S1806-37132015000004480

5. Dela Bianca AC, Wandalsen GF, Miyagi K, Camargo L, Cezarin D, Mallol J, Solé D. International Study of Wheezing in Infants (EISL): validation of written questionnaire for children aged below 3 years. J Investig Allergol Clin Immunol. 2009;19:3542. 


\section{Psychometric Validation of the Spanish Version of the DHRQoL Questionnaire}

Gastaminza G ${ }^{1,5}$, Ruiz-Canela $\mathrm{M}^{2}$, Baiardini I ${ }^{3}$, Andrés-López B ${ }^{4}$, Corominas $\mathrm{M}^{4,5}$

${ }^{1}$ Allergy Department, Clinica Universidad de Navarra, Pamplona, Spain

${ }^{2}$ Department of Preventive Medicine and Public Health, University of Navarra, Pamplona, Spain

${ }^{3}$ Allergy and Respiratory Diseases Clinic, DIMI, University of Genoa, IRCCS AOU San Martino-IST, Genova, Italy

${ }^{4}$ Allergy Unit, Hospital Universitari de Bellvitge, IDIBELL, L'Hospitalet de Llobregat, Spain

${ }^{5}$ Spanish Society of Allergy and Clinical Immunology (SEAIC), Drug Allergy Committee

J Investig Allergol Clin Immunol 2016; Vol. 26(5): 322-323 doi: 10.18176/jiaci.0079

Key words: Drug allergy. Health-related quality of life. Psychometric validation. Questionnaire. Adverse drug reactions.

Palabras clave: Alergia a medicamentos. Calidad de vida relacionada con la salud. Validación psicométrica. Cuestionario. Reacciones adversas a medicamentos.

Drug allergy is a very common condition faced by both primary care physicians [1] and hospital physicians [2] worldwide. Drug allergy is further complicated by the underlying disease, which frequently prevents the use of the usual first-line treatments. Furthermore, allergists know that patients who have experienced an allergic drug reaction, especially those who have had a severe reaction, are increasingly fearful of new allergic reactions and therefore tend to avoid taking any type of medication. In a previous study [3], we validated the Spanish version of the Drug Hypersensitivity Quality of Life (DHRQoL) questionnaire, which was developed in Italy by Baiardini et al [4]. In the present paper, we report the results of our psychometric validation of the questionnaire.

A total of 30 consecutive patients were admitted to the Allergology Service of Bellvitge Hospital, L'Hospitalet de Llobregat, Barcelona, Spain from February to April 2015. Each patient was asked to fill in the DHRQoL questionnaire on 2 occasions separated by a 5 -hour interval. No allergy tests were carried out during the interval, and no information that could have influenced the patient's answers to the questionnaire was provided.

The Cronbach $\alpha$ ( 0 to 1$)$ was used to determine the questionnaire's internal consistency [5]. A factor analysis was also carried out to determine whether 1 or several dimensions could be measured by the questionnaire. Quartimax rotation was used because the existence of a general factor was suspected [4].

Moreover, the Lin correlation coefficient (CC) was used to measure the degree of consistency between the answers to both questionnaires (baseline and retest). A figure was also created following the Bland-Altman plot in order to determine concordance between the questions at 2 different points (baseline and retest).

Of the 30 patients who completed the DHRQoL questionnaire, 20 also completed the Psychological General Well-being Index (PGWBI) questionnaire, which consists of 22 items grouped in 6 dimensions: anxiety, depressed mood, positive well-being, self-control, general health, and vitality [6].

The Spearman correlation coefficient was used to analyze the correlation between the DHRQoL and the dimensions of the PGWBI.

The study population comprised 30 patients, 20 of whom were women, with a mean (SD) age of 45 (15.5) years. The median (IQR) time since the allergic reaction was 6 months (3-60 months).

Five of the 30 patients $(17 \%)$ had experienced an anaphylactic reaction, $14(47 \%)$ had developed urticaria, and the rest (36\%) had experienced other types of reactions. The allergist's suspicions before performing the allergy test, combined with the information from each patient's medical history, indicated that 14 patients $(47 \%)$ may have experienced a drug allergy and that in the remaining 16 patients, the reaction was not a true allergic reaction.

The global result of the baseline DHRQoL questionnaire in all patients was a median (IQR) score of 29 (27-39) and that of the retest questionnaire was a median score of 27 (22-33). Patients with anaphylaxis obtained a median score of 30 (27-35), and those who had not experienced an anaphylactic reaction obtained a median score of 28 (27-39). Furthermore, patients who were suspected of having had a real allergic reaction obtained a median score of 28 (26-35), whereas those in which an allergic reaction was not suspected obtained a median score of $30(28-43)$.

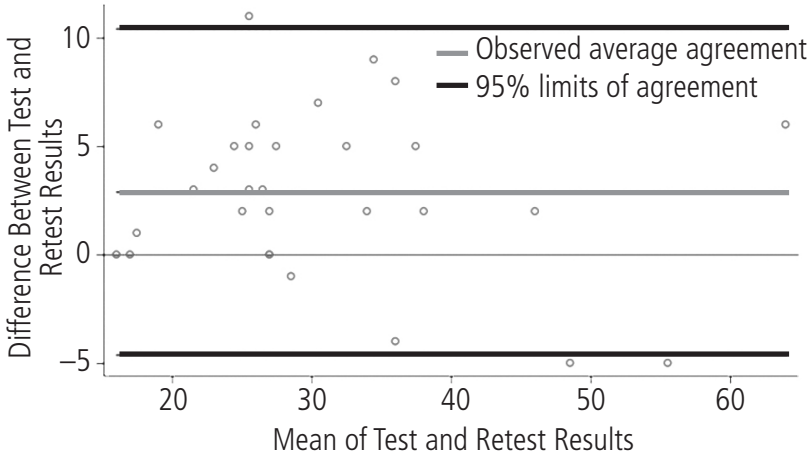

$\mathrm{y}=0$ is line of perfect average agreement

The line commencing at zero indicates the expected values (the same in both tests), and the thicker gray line indicates the result obtained from the difference, with a mean value of 2.9 (3.8) points. The agreed minimum and maximum limits were -4.6 and 10.6 , respectively.

Figure. Bland-Altman concordance analysis of the difference between both consecutive questionnaires completed by each patient and the mean score of both tests for each patient. 
The global CC was 0.911 (95\%CI, 0.852-0.970). The question with the greatest concordance was number 13 (CC, 0.919; 95\%CI, 0.863-0.975), and that with the lowest concordance was number 7 (CC, $0.575 ; 95 \% \mathrm{CI}, 0.335-0.815$ ).

The Figure shows the results of the Bland-Altman concordance analysis. The mean difference between the initial test and the retest was 2.9 (3.8) points. Three patients fell outside the expected limits of \pm 2 SD ( -4.6 to 10.4 ).

Based on the Cronbach $\alpha$, the questionnaire's global internal consistency was 0.916 . Question 3 had the greatest influence (Cronbach $\alpha$ without this question, 0.905), although high internal consistency was observed in general.

The factor analysis carried out with quartimax rotation revealed 3 dimensions: one included all questions except numbers 2 and 9; another included questions 2, 5, 9, and 10; and a third dimension included questions 1,4 , and 7 .

A poor correlation was observed between the results of both questionnaires (Spearman $\rho,-0.279 ; P=.234$ ). Analysis of the correlation between the DHRQoL questionnaire and the 6 dimensions of the PGWBI questionnaire revealed a negative and statistically significant correlation for the depressed mood dimension $(\rho,-0.531 ; P=.016)$.

This study confirms that the DHRQoL questionnaire has marked internal consistency (Cronbach $\alpha, 0.916$ ), which is very similar to that obtained by Baiardini et al [4] (0.928) [4]. Additionally, the test-retest analysis revealed a high degree of concordance, as in the case of the original study carried out to develop the questionnaire [4].

Our factor analysis revealed 3 dimensions. One included all questions except question 2, which is consistent with the data reported by Baiardini et al [4], who studied the questionnaire as a whole. The other 2 dimensions analyzed patients' fear of receiving medications (questions 2, 5, 9, and 10) and the limitations that a possible drug allergy entails for them (questions 1, 4, and 7). These dimensions must be confirmed by means of a confirmatory factor analysis.

The comparison of the results of the DHRQoL and PGWBI questionnaires revealed a negative - albeit not statistically significant - correlation with the depressed mood dimension. This finding differs from that reported by Baiardini et al [4], whose study did not establish a correlation between the DHRQoL questionnaire and any of the PGWBI dimensions.

In conclusion, we confirmed that the DHRQoL questionnaire has the psychometric validity required for a questionnaire developed following appropriate methodology, as in the case of its original Italian version. In the future, it would be of great interest to carry out additional studies to determine to what extent an allergic drug reaction affects the quality of life of the patient who experiences it. It would also be interesting to determine whether the questionnaire's results depend on the type of drug, the severity of the allergic reaction, or other factors.

\section{Funding}

The authors declare that no funding was received for the present study.

\section{Conflicts of Interest}

The authors declare that they have no conflicts of interest.

\section{References}

1. Gandhi TK, Weingart SN, Borus J, Seger AC, Peterson J, Burdick E, Seger DL, Shu K, Federico F, Leape LL, Bates DW. Adverse drug events in ambulatory care. $N$ Engl J Med. 2003;348:1556-64.

2. Thong BY, Tan TC. Epidemiology and risk factors for drug allergy. Brit J Clin Pharmacol. 2011;71:684-700.

3. Gastaminza G, Herdman M, Baiardini I, Braido F, Corominas M. Cross-cultural adaptation and linguistic validation of the Spanish version of the drug hypersensitivity quality of life questionnaire. J Invest Allergol Clin Immunol. 2013;23:50810.

4. Baiardini I, Braido F, Fassio O, Calia R, Giorgio WC, Romano A, DrHy-Q PROs Research Italian Group. Development and validation of the Drug Hypersensitivity Quality of Life Questionnaire. Ann Allergy Asthma Immunol. 2011;106:3305.

5. Cronbach LJ. Coefficient alpha and the internal structure of tests. Psychometrika. 1951;16:297-334.

6. Chassany O, Dubois D, Wu A. The psychological general wellbeing index (PGWBI) user manual. In: 2004. MRI, editor. Lyon (FR) Available at: http://178.23.156.107:8085/Instruments_ files/USERS/pgwbi.pdf.

Manuscript received April 11, 2016; accepted for publication May 18, 2016.

Gabriel Gastaminza Departamento de Alergología Clínica Universidad de Navarra Pío XII, 36 31008 Pamplona, Spain E-mail: Gastaminza@unav.es 


\section{A Protocol for Induction of Tolerance to Apomorphine in Patients With Parkinson Disease and Hypersensitivity to Apomorphine}

Gutiérrez-Fernández $\mathrm{D}^{1}$, Moreno-Ancillo $\mathrm{A}^{2}$, FoncubiertaFernández $\mathrm{A}^{3}$, Medina-Varo $\mathrm{F}^{1}$, Andrés-García JA ${ }^{1}$, FernándezAnguita $\mathrm{MJ}^{1}$

${ }^{1}$ Hospital Universitario Puerta del Mar, Cadiz, Spain

${ }^{2}$ Hospital Nuestra Señora del Prado, Talavera de la Reina, Spain

${ }^{3}$ Centro de Salud Dr Joaquín Pece, San Fernando, Spain

J Investig Allergol Clin Immunol 2016; Vol. 26(5): 324-325 doi: $10.18176 /$ jiaci.0081

Key words: Apomorphine. Parkinson disease. Hypersensitivity. Desensitization. Tolerance induction protocol.

Palabras clave: Apomorfina. Enfermedad de Parkinson. Hipersensibilidad. Desensibilización. Protocolo de inducción de tolerancia.

Apomorphine, a short-acting dopamine D1 and D2 receptor agonist, was the first dopamine receptor agonist used to treat Parkinson disease. Subcutaneous apomorphine is currently used for the management of sudden, unexpected, and refractory levodopa-induced off-states in fluctuating Parkinson disease, either as intermittent rescue injections or continuous infusions [1-3]. Some of the most frequent adverse effects of long-term apomorphine therapy are orthostatic hypotension, nausea, fibrotic nodules at the site of infusion, and sedation [3]. Cutaneous nodules observed in patients with Parkinson disease treated with continuous subcutaneous apomorphine are sometimes characterized by florid eosinophilic panniculitis; however, patch testing is universally negative, and the $\operatorname{IgE}$ levels are normal [4]. Delayed hypersensitivity reactions with positive patch test results [5-7] and immediate hypersensitivity reactions have been reported [8].

We present a protocol for induction of tolerance to apomorphine in 2 patients who experienced generalized urticarial reactions to the drug. The first patient (reported elsewhere [8]) was a 56-year-old man with uncontrolled Parkinson disease. Apomorphine injections were administered intermittently via pen over 6 months as rescue therapy for sudden off periods. This regimen was followed by continuous infusion at a rate of $1 \mathrm{mg} / \mathrm{h}$ and then increased according to the patient's response. The drug was administered continuously for an additional month via an apomorphine pump with an infusion rate of $2.5 \mathrm{mg} / \mathrm{h}$ for 12 hours per day while the patient was awake, stopping at night. The patient developed raised itchy wheals on the underarms, groin, chest, lower back, and buttocks approximately 20 minutes after he reached the cumulative dose of $4 \mathrm{mg}$ apomorphine administered at $2.5 \mathrm{mg} / \mathrm{h}$ [8]. The second patient was a 58-year-old man with Parkinson disease treated with continuous infusion of apomorphine for motor fluctuations and dyskinesia. His infusion was programmed based on a 12-hour regimen; however, after the first month of therapy, he experienced progressive generalized itchy wheals when the infusion rate was $3 \mathrm{mg} / \mathrm{h}$. Apomorphine was stopped, and the cutaneous symptoms improved, although Parkinson disease worsened. The patient also had allergic rhinitis due to mite sensitization. He had tolerated tramadol. Neither patient had a history of idiopathic or nonsteroidal anti-inflammatory drug-related anaphylactic reactions or life-threatening vascular collapse. Neither had previously experienced urticaria or angioedema. The patients were not taking antihypertensive medication (angiotensin-converting enzyme inhibitors, $\beta$-blockers, or angiotensin receptor blockers). Apomorphine was considered essential for treatment in both patients.

Allergic-like reactions with apomorphine are rare; therefore, we wanted to record as much information as possible in order to design a desensitization protocol. As we had previously reported [8], patch, prick, intradermal, and challenge testing were considered necessary to collect this information. We performed skin prick tests with apomorphine $10 \mathrm{mg} / \mathrm{mL}$ and intradermal tests with diluted apomorphine at concentrations of $0.001 \mathrm{mg} / \mathrm{mL}, 0.01 \mathrm{mg} / \mathrm{mL}$, and $0.1 \mathrm{mg} / \mathrm{mL}$. An intradermal test at a dilution of $0.1 \mathrm{mg} / \mathrm{mL}$ resulted in a $6-\mathrm{mm}$ wheal in the first patient, as previously reported [8]. A negative response was detected in the second patient and 14 controls ( 6 atopic and 8 nonatopic). Patch testing was performed with apomorphine diluted in water to $50 \%, 5 \%$, and $1 \%$ and in petrolatum $5 \%$ and $1 \%$. The results of patch testing with apomorphine were negative in both patients. A single-blind, placebo-controlled challenge test was performed with subcutaneous apomorphine. Symptoms reappeared in both patients. In the first patient, apomorphine produced a positive response after approximately 20 minutes [8]. The second patient experienced urticaria and angioedema 30 minutes after receiving $7 \mathrm{mg}$ of apomorphine and was treated with $5 \mathrm{mg}$ of intravenous dexchlorpheniramine maleate and $30 \mathrm{mg}$ of oral deflazacort. As the commercial preparation of apomorphine contains $0.093 \%$ sodium bisulfite, the patients underwent a double-blind, placebo-controlled challenge with sodium metabisulfite, and the results were negative. Although skin testing was negative in the second patient, hypersensitivity to apomorphine was diagnosed taking into account the clinical presentation and reproducibility of the reaction upon reexposure.

A tolerance induction protocol was designed with increasing concentrations of apomorphine $(0.03 \mathrm{mg} / \mathrm{mL}$ to $10 \mathrm{mg} / \mathrm{mL}$ ) (Table). The route of administration was subcutaneous, and each dose was administered intermittently. The patients were premedicated with $10 \mathrm{mg}$ of cetirizine 1 hour before starting the protocol. The initial dose was $0.003 \mathrm{mg}$ of apomorphine, and intermittent subcutaneous doses were increased every 15 minutes. The target dose was $3 \mathrm{mg}$ (cumulative dose $4.998 \mathrm{mg}$ of apomorphine). During the third step, the first patient experienced mild pruritus, which resolved with intravenous dexchlorpheniramine maleate (Table). At the end of the procedure, subcutaneous apomorphine infusion was initially continued at $1 \mathrm{mg} / \mathrm{h}$ and increased by $0.5 \mathrm{mg} / \mathrm{h}$ every 4 hours depending on the patient's response. The first patient continued at $2.5 \mathrm{mg} / \mathrm{h}$ for 12 hours per day (no infusion at night) and was completely able to tolerate apomorphine. The second patient continued at $3 \mathrm{mg} / \mathrm{h}$ for 12 hours per day (no infusion at night), with complete tolerance of apomorphine. 
Table. Tolerance Induction Protocol for Subcutaneous Apomorphine

\begin{tabular}{|c|c|c|c|c|c|c|}
\hline Step $^{\mathrm{a}}$ & Solution, $\mathrm{mg} / \mathrm{mL}$ & Amount, mL & Dose, mg & $\begin{array}{l}\text { Cumulative } \\
\text { Dose, mg }\end{array}$ & $\begin{array}{l}\text { Findings } \\
\text { Patient } 1\end{array}$ & $\begin{array}{l}\text { Findings } \\
\text { Patient } 2\end{array}$ \\
\hline 1 & 0.03 & 0.1 & 0.003 & 0.003 & None & None \\
\hline 2 & 0.03 & 0.5 & 0.015 & 0.018 & None & None \\
\hline 3 & 0.3 & 0.1 & 0.03 & 0.048 & Mild pruritus ${ }^{\mathrm{b}}$ & None \\
\hline 4 & 0.3 & 0.5 & 0.15 & 0.198 & None & None \\
\hline 5 & 3 & 0.1 & 0.3 & 0.498 & None & None \\
\hline 6 & 3 & 0.5 & 1.5 & 1.998 & Mild dyskinesia & None \\
\hline 7 & 10 & 0.3 & 3 & 4.998 & None & None \\
\hline
\end{tabular}

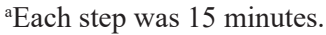

${ }^{\mathrm{b}}$ Treated with intravenous dexchlorpheniramine $5 \mathrm{mg}$.

Both patients tolerated continuous subcutaneous apomorphine for more than 12 months after completion of the protocol.

We report 2 cases of hypersensitivity reactions after administration of apomorphine and present the results of a rapid protocol for induction of tolerance to this drug. To our knowledge, no cases of desensitization or induction of tolerance to apomorphine have been reported to date. The cumulative therapeutic dose was reached in 2 hours, and the protocol was completed successfully. The protocol was administered because no alternative treatments were available for Parkinson disease in these cases. The patients responded well to the desensitization procedure and completed the protocol safely.

Apomorphine can cause drug-related reactions, but the exact etiology of these events remains unclear. Both patients in the present report were successfully desensitized to apomorphine. In the first [8], the underlying cause seemed to be an IgE-mediated mechanism; in the second, it was not possible to define the underlying mechanism. However, hypersensitivity to apomorphine was also diagnosed taking into account the clinical presentation and challenge test result.

The desensitization protocol, which was considered an induction tolerance protocol in the second case, worked well in both patients. Therefore, it can be recommended for other cases of adverse reactions to apomorphine.

\section{Funding}

The authors declare that no funding was received for the present study.

\section{Conflicts of Interest}

The authors declare that they have no conflicts of interest.

\section{References}

1. Millan MJ, Maiofiss L, Cussac D, Audinot V, Boutin JA, Newman-Tancredi A. Differential actions of antiparkinson agents at multiple classes of monoaminergic receptor. I. A multivariate analysis of the binding profiles of 14 drugs at 21 native and cloned human receptor subtypes. J Pharmacol Exp Ther. 2002;303:791-804.

2. Ribaric S. The Pharmacological Properties and Therapeutic Use of Apomorphine. Molecules. 2012;17:5289-309.

3. Deleu D, Hanssens $Y$, Northway MG. Subcutaneous apomorphine: An evidence-based review of its use in Parkinson's disease. Drugs Aging. 2004;21:687-709.

4. Acland KM, Churchyard A, Fletcher CL, Turner K, Lees A, Dowd PM. Panniculitis in association with apomorphine infusion. $\mathrm{Br}$ J Dermatol. 1998;138:480-2.

5. Garcia-Gavin J, González-Vilas D, Fernández-Redondo V, Campano L, Toribio J. Allergic contact dermatitis caused by apomorphine hydrochloride in a career. Contact Dermatitis. 2010;63:112-5.

6. Carboni GP, Contri P, Davalli R. Allergic contact dermatitis from apomorphine. Contact Dermatitis. 1997;36:177-8.

7. Dahlquist I. Allergic reactions to apomorphine. Contact Dermatitis 1977;3:349-50.

8. Gutiérrez D, Foncubierta A, Espinosa R, Astorga S, Leon A, Fernández S. Immediate type 1 hypersensitivity to apomorphine: a case report. J Investig Allergol Clin Immunol. 2011;21:317-29.

Manuscript received December 15, 2015; accepted for publication May 19, 2016.

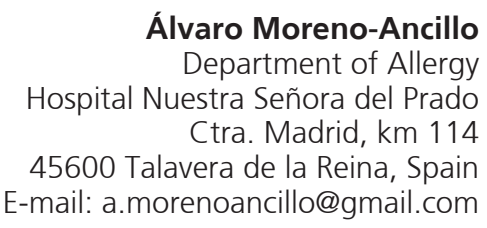

Álvaro Moreno-Ancillo (

Ctra Madrid km 114 E-mail: a.morenoancillo@gmail.com 


\section{Aquagenic Urticaria: Report of a Case in an Adolescent Girl}

Muinelo A, Pérez O, Vila L

Pediatric Allergy Unit, Hospital Materno-Infantil Teresa Herrera, La Coruña, Spain

J Investig Allergol Clin Immunol 2016; Vol. 26(5): 326-327 doi: $10.18176 /$ jiaci.0082

Key words: Aquagenic urticaria, adolescent, antihistamines, physical urticaria.

Palabras clave: Urticaria acuagénica, adolescente, antihistamínicos, urticaria física.

Aquagenic urticaria is a rare condition. Fewer than 50 cases have been published in the literature and most of these have been in the form of case reports [1]. The clinical picture is characterized by small wheals $(1-3 \mathrm{~mm})$, erythema, and intense pruritus occurring within 10 to 30 minutes of exposure to water, regardless of its temperature. The condition resolves within 30 to 60 minutes after the water is eliminated from the skin. Systemic manifestations are rare but have been reported [2]. We report the first case of aquagenic urticaria in a Spanish adolescent.

A 12-year-old girl presented with a 2-month history of erythema, pruritus, and small wheals that developed on her face, neck, and chest after contact with water (showering and diving into a pool). The symptoms appeared within 10 to 20 minutes of contact with water, regardless of temperature, and disappeared without medication in less than an hour.

She did not report angioedema, wheezing, or dyspnea during these episodes. There was also no history of urticaria with physical exercise, sweating, heat, or emotional stress. She tolerated exposure to cold temperatures. There was no present personal or family history of atopy, and none of the girl's relatives reported similar skin reactions related to water exposure.

The physical examination was unrevealing, and dermographism was negative. Additional studies, including a complete blood count and urine analysis, were normal. A water challenge test was performed by applying a compress soaked in tap water at $35^{\circ} \mathrm{C}$ on the upper chest. Within 20 minutes the patient reported pruritus and developed a micropapular eruption and erythema in the contact area (Figure), confirming the suspected diagnosis of aquagenic urticaria.

Short showers or baths were recommended, and we prescribed medical treatment with oral levocetirizine only for episodes of lasting or uncomfortable urticaria.

Aquagenic urticaria is an uncommon type of physical urticaria that usually appears during puberty or several years later and is more common in female patients [3-5]. Most cases are sporadic, although a small number of familial cases have been reported [6,7]. Its pathogenesis is not fully understood, although several mechanisms have been proposed. Shelley

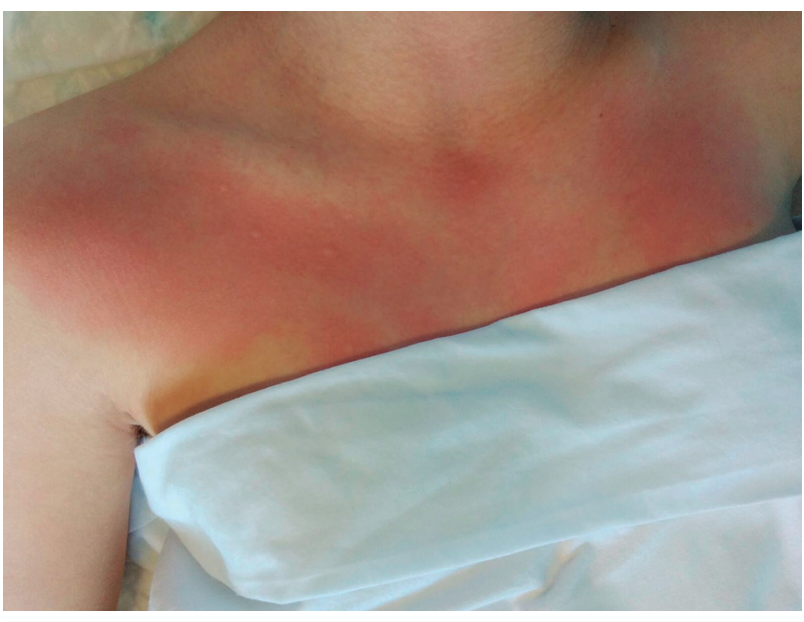

Figure. Wheal and flare reaction 20 minutes after applying a compress soaked in tap water at $35^{\circ} \mathrm{C}$ to the upper chest.

and Rawnsley [8], who described the first cases of aquagenic urticaria in 1964, postulated that water might interact with sebum in the stratum corneum to form a substance capable of acting as a direct mast cell degranulator, resulting in histamine release. Czarnetzki et al [9], in turn, hypothesized that a water soluble antigen at the epidermal layer might diffuse into the dermis, resulting in histamine release from mast cells. Recently, in vitro basophil activation by flow cytometry assay was detected after a water challenge test in a patient with aquagenic urticaria [10].

Cold urticaria and cholinergic urticaria are major considerations in the differential diagnoses for aquagenic urticaria. This condition must be distinguished from aquagenic pruritus, in which intense itching occurs after contact with water, but without visible skin lesions $[1,6]$. The standard test for aquagenic urticaria is the application of a water compress at $35^{\circ} \mathrm{C}$ to the upper body for 30 minutes. Keeping the compress at room temperature avoids confusion with cold-induced or local heat urticaria [1].

Antihistamines are usually recommended to treat aquagenic urticaria, although response varies from one patient to the next. In refractory cases, UV radiation (psoralen-UV-A therapy or UV-B) alone or in combination with antihistamines, barrier methods to protect the skin from water, and even omalizumab, have been successfully used [1,5].

In the case of our patient, given the limited impact of symptoms on her life and their spontaneous resolution within minutes, we indicated symptomatic treatment with antihistamines only if skin lesions worsened.

\section{Funding}

The authors declare that no funding was received for the present study.

\section{Conflicts of Interest}

The authors declare that they have no conflicts of interest. 


\section{References}

1. Dice J, MD. Physical urticaria. Immunol Allergy Clin N Am. 2004;24:225-46.

2. Luong K, Nguyen LTH. Aquagenic urticaria: report of a case and review of the literature. Ann Allergy Asthma Immunol. 1998;80:483-5.

3. Park H, Kim SA, Yoo DS, Kim JW, Kim CW , Kim SS, Hwang $J$, Lee JY, Choi YJ. Aquagenic urticaria: a report of two cases. Ann Dermatol. 2011 Dec; 23. Vol 23. Suppl 3. S371-4.

4. Yavuz ST, Sahiner UM, Tuncer A, Sackesen C. Aquagenic urticaria in 2 adolescents. J Investig Allergol Clin Immunol. 2010;20(7):624-5.

5. Rorie A, Gierer S. A case of aquagenic urticaria successfully treated with omalizumab. J Allergy Clin Immunol Pract. 2016;May-Jun;4(3):547-8.

6. Kai A, Carsten F. Aquagenic urticaria in twins. World Allergy Organ J. 2013;6(1):2.

7. Treudler R, Tebbe B, Steinhoff M, Orfanos CE. Familial aquagenic urticaria associated with familial lactose intolerance. J Am Acad Dermatol. 2002;47(4):611-3.

8. Shelley WB, Rawnsley HM. Aquagenic urticaria. Contact sensitivity reaction to water. JAMA. 1964;189:895-8.

9. Czarnetzki BM, Breetholt KH, Traupe H. Evidence that water acts as a carrier for an epidermal antigen in aquagenic urticaria. J AM Acad Dermatol. 1986;15(4):623-7.

10. Frances AM, Fiorenza G, Frances RJ. Aquagenic urticarial: report of a case. Allergy and Asthma Proc. 2004;25(3):195-7.

I Manuscript received March 15, 2016; accepted for publication, May 19, 2016.

Leticia Vila Sexto

Unidad de Alergia Infantil Hospital Materno-Infantil Teresa Herrera

C/As Xubias $s / n$

15006 La Coruña

Spain

E-mail: leticia.vila.sexto@sergas.es

\section{Yogurt in the Treatment of $\beta$-Lactoglobulin-Induced Gastrointestinal Cow's Milk Allergy}

Poza-Guedes $\mathrm{P}^{1}$, Barrios $\mathrm{Y}^{2}$, González Pérez $\mathrm{R}^{1}$, Sánchez-Machín $\mathrm{I}^{1}$, Franco $\mathrm{A}^{2}$, Matheu $\mathrm{V}^{1}$

${ }^{1}$ Consulta de Alergia Infantil, Unidad de Alergología-Norte, Hospital del Tórax/Ofra, San Cristóbal de La Laguna, Spain

${ }^{2}$ Immunology, Hospital Universitario de Canarias, La Laguna, Spain

J Investig Allergol Clin Immunol 2016; Vol. 26(5): 327-329 doi: 10.18176/jiaci.0083

Key words: Cow's milk allergy. Gastrointestinal allergy. B-Lactoglobulin. IgE-mediated allergy.

Palabras clave: Alergia a leche de vaca. Alergia gastrointestinal. Betalactoglobulina. Alergia mediada por lgE.

The prevalence of food allergy (FA) is around 3.5\% in the general population and $5 \%-8 \%$ in children [1]. Cow's milk (CM) allergy is particularly noteworthy because of the role of this food in children's diet, especially when the child is not breastfed.

Anaphylaxis is the most severe allergic reaction to CM [2] and is currently treated with oral immunotherapy [3]. However, many patients are affected by gastrointestinal (GI) conditions only, including IgE-mediated [4] and nonIgE-mediated disorders [5], which are induced by food antigens with a marked clinical overlap between them [1]. The disorders include eosinophilic esophagitis, eosinophilic gastroenteritis [6], allergic proctocolitis [6], and food proteininduced enterocolitis syndrome [6]. The most common GI condition is immediate GI hypersensitivity, which involves IgE-mediated clinical manifestations that can occur within minutes (immediate reaction) in the upper GI tract or up to several hours later (delayed reaction) in the lower GI tract. Immediate GI hypersensitivity is usually considered a variant of anaphylaxis [7]. The aims of this study were to assess the follow-up of patients with GI allergy mediated by sIgE against $\beta$-lactoglobulin [7] after 6 months of dairy products (Group A) and to compare it with that of patients who did not undergo an intervention (Group B, only elimination of CM).

In our area (northern Tenerife, Spain), with 105910 inhabitants aged $<14$ years, we selected 40 patients from our center (Infant Allergy Clinic [Northern Region], Tenerife, Spain) who experienced specific GI symptoms 30-120 minutes after intake of a glass of CM. The inclusion criteria also comprised serum specific $\operatorname{IgE}(\mathrm{sIgE})>0.1 \mathrm{kU}_{\mathrm{A}} / \mathrm{L}$ to whole $\mathrm{CM}$ or some of the CM proteins such as casein (CAS) and the main whey proteins $\alpha$-lactalbumin (ALA) and $\beta$-lactoglobulin (BLG).

The exclusion criteria included a clinical history of extraintestinal symptoms (cutaneous, ocular, respiratory, and/or cardiovascular) immediately after a glass of CM or $\operatorname{sigE}<0.1 \mathrm{kU}_{\mathrm{A}} / \mathrm{L}$ to $\mathrm{CM}, \mathrm{CAS}, \mathrm{ALA}$, and BLG, as well as 
Table. Levels of specific lgE in patients from both groups (first line). Levels of specific lgE in group A (second line) treated with daily yogurt and group B (third line) treated with total restriction of CM products at baseline (day 0) and after 6 months (6 mo). Data are expressed as mean specific lgE levels in each group

\begin{tabular}{|c|c|c|c|c|c|c|c|c|}
\hline \multirow{2}{*}{$\begin{array}{l}\text { GI phenotype } \\
\text { Total patients } \\
\mathrm{N}=40\end{array}$} & \multicolumn{8}{|c|}{ Specific IgE } \\
\hline & \multicolumn{2}{|c|}{$\begin{array}{c}\mathrm{CM} \\
\mathrm{n}=32 \\
1.36\end{array}$} & \multicolumn{2}{|c|}{$\begin{array}{c}\text { BLG } \\
n=40 \\
4.13\end{array}$} & \multicolumn{2}{|c|}{$\begin{array}{c}\text { CAS } \\
\mathrm{n}=28 \\
1.12\end{array}$} & \multicolumn{2}{|c|}{$\begin{array}{c}\text { ALA } \\
\mathrm{n}=22 \\
1.09\end{array}$} \\
\hline $\begin{array}{l}\text { Group A } \\
n=25\end{array}$ & $\begin{array}{c}\text { Day 0 } \\
1.35\end{array}$ & $\begin{array}{c}6 \mathrm{mo} \\
1.2\end{array}$ & $\begin{array}{c}\text { Day 0 } \\
6.51\end{array}$ & $\begin{array}{c}6 \mathrm{mo} \\
4.7\end{array}$ & $\begin{array}{c}\text { Day 0 } \\
1.51\end{array}$ & $\begin{array}{c}6 \mathrm{mo} \\
0.52\end{array}$ & $\begin{array}{c}\text { Day 0 } \\
0.76\end{array}$ & $\begin{array}{c}6 \mathrm{mo} \\
0.50\end{array}$ \\
\hline $\begin{array}{l}\text { Group B } \\
n=15\end{array}$ & $\begin{array}{c}\text { Day 0 } \\
1.06\end{array}$ & $\begin{array}{c}6 \mathrm{mo} \\
1.55\end{array}$ & $\begin{array}{c}\text { Day 0 } \\
3.38\end{array}$ & $\begin{array}{l}6 \mathrm{mo} \\
5.88\end{array}$ & $\begin{array}{c}\text { Day 0 } \\
1.29\end{array}$ & $\begin{array}{l}6 \mathrm{mo} \\
3.98\end{array}$ & $\begin{array}{c}\text { Day 0 } \\
1.53\end{array}$ & $\begin{array}{c}6 \mathrm{mo} \\
1.8\end{array}$ \\
\hline
\end{tabular}

Abbreviations: ALA, $\alpha$-lactalbumin; BLG, $\beta$-lactoglobulin; CAS, casein; CM, cow's milk.

a diagnosis of celiac disease based on the presence of $\operatorname{IgA}$ antitransglutaminase antibodies (ELiA Immunocap 250, Phadia) and antideaminated gliadin antibodies (Quanta Lite Gliadin IgA II) and the results of a lactose intolerance inhalation test.

Skin prick tests (SPTs) with commercial extracts (BIAL) were performed with whole CM $(5 \mathrm{mg} / \mathrm{mL}), \mathrm{CAS}(10 \mathrm{mg} / \mathrm{mL})$, ALA $(5 \mathrm{mg} / \mathrm{mL})$, and BLG $(1 \mathrm{mg} / \mathrm{mL})$. The concentration of total immunoglobulin $\mathrm{E}$ and $\mathrm{sIgE}$ against whole CM, CAS, ALA, and BLG in serum was measured (ImmunoCAP, Phadia $\mathrm{AB}$ ) based on a detection limit of $0.1 \mathrm{kU} / \mathrm{L}$.

Children underwent an open food challenge (OFC) with $\mathrm{CM}$ at the hospital allergy unit under clinical observation by experienced personnel. All participants were observed for the 24 hours following the OFC at home by their parents, who could phone the allergy unit at any time. Patients with a positive OFC result were offered a new OFC with yogurt under the same conditions (Group A). Patients who refused the OFC with yogurt were assigned to an elimination diet. During the 6-month study period, participants in the elimination diet group (Group B), were kept on a CM-free diet, whereas those in the dairy products group (Group A) were exposed daily to yogurt. All patients and tutors gave their written informed consent. The protocol was approved by the Regional Ethics Committee (COLIVAC HUNSC P.I-35/11; 24/14).

The most prevalent symptom was abdominal cramps in 36 out of 40 patients $(90 \%)$, followed by food refusal in 32 patients $(80 \%)$, abdominal discomfort or distention in 30 patients $(75 \%)$, diarrhea in 10 patients $(25 \%)$, and constipation in 5 patients $(12.5 \%)$.

SPT yielded positive results in only 14 patients $(35 \%)$. The wheal was greater than $3 \mathrm{~mm}$ with CM in 12 patients, CAS in 4 patients, ALA in 6 patients, and BLG in 8 patients.

Specific $\operatorname{IgE}(\mathrm{sIgE})$ to whole $\mathrm{CM}$ was $>0.10 \mathrm{kU}_{\mathrm{A}} / \mathrm{L}(>0.1)$ in 32 patients and $<0.1 \mathrm{kU}_{\mathrm{A}} / \mathrm{L}(<0.1)$ in 8 patients. Mean $(\mathrm{SD})$ sIgE against whole CM was $1.36(3.34) \mathrm{kU}_{\mathrm{A}} / \mathrm{L}$. sIgE to CAS was $>0.10 \mathrm{kU}_{\mathrm{A}} / \mathrm{L}$ in 28 patients and $<0.1 \mathrm{kU}_{\mathrm{A}} / \mathrm{L}$ in 12 patients, with an average of $1.12(3.21) \mathrm{kU}_{\mathrm{A}} / \mathrm{L}$. sIgE to ALA was $>0.10 \mathrm{kU}_{\mathrm{A}} / \mathrm{L}$ in 22 patients and $0.1 \mathrm{kU}_{\mathrm{A}} / \mathrm{L}$ in 18 patients, with an average of $1.09(2.45) \mathrm{kU}_{\mathrm{A}} / \mathrm{L}$. $\operatorname{sigE}$ to BLG was $>0.10 \mathrm{kU}_{\mathrm{A}} / \mathrm{L}$ in 40 patients, with an average of $4.13(8.30) \mathrm{kU}_{\mathrm{A}} / \mathrm{L}$. No patients had $\operatorname{sIgE}$ to $\mathrm{BLG}<0.1 \mathrm{kU}_{\mathrm{A}} / \mathrm{L}$ (Table).
OFC with whole CM in patients in Group A $(n=25)$ was positive, reproducing the initial symptoms of the previous clinical history. The results of OFC with yogurt in patients in Group A were all negative, with good tolerance. Parents/ tutors agree that patients were able to take a daily yogurt for 6 months. No symptoms or reactions were recorded after 6 months, and all patients tolerated yogurt every day. Mean levels of sIgE to BLG decreased from $6.51 \mathrm{kU}_{\mathrm{A}} / \mathrm{L}$ to $4.7 \mathrm{kU}_{\mathrm{A}} / \mathrm{L}(P<.05)$. Levels of sIgE to CAS also decreased from $1.51 \mathrm{kU}_{\mathrm{A}} / \mathrm{L}$ to $0.52 \mathrm{kU}_{\mathrm{A}} / \mathrm{L}$.

The results of OFC with whole CM in patients in Group B $(n=15)$ were all positive, mimicking the symptoms in the previous clinical history. Parents/tutors reported that patients maintained a diet that eliminated $\mathrm{CM}$ and dairy products. After 6 months, no patients experienced symptoms or reactions, and mean levels of sIgE to BLG increased from $3.3 \mathrm{kU}_{\mathrm{A}} / \mathrm{L}$ to $5.8 \mathrm{kU}_{\mathrm{A}} / \mathrm{L}(P<.05)$. Similarly, levels of $\mathrm{sIgE}$ to CAS also increased from $1.29 \mathrm{kU}_{\mathrm{A}} / \mathrm{L}$ to $3.98 \mathrm{kU}_{\mathrm{A}} / \mathrm{L}(P<.01)$.

The possible prevalence of $\beta$-lactoglobulin-induced GI allergy has been reported to be around $11 \%$ in patients with $\mathrm{CM}$ allergy [7]. Since BLG is absent or very decreased in many yogurts [8], probably because of polymerization in tetramers of BLG [9], we proposed a 6-month yogurt-only diet after checking tolerance to $\mathrm{CM}$ in an OFC. After 6 months, tolerability was excellent in Group A, and levels of SIgE to BLG had decreased significantly. Moreover, sIgE to CAS also tended to decrease. In Group B, levels of sIgE to both BLG and CAS increased significantly. The significance of these trends should be investigated in more detail. In this report, we used yogurt with modified proteins to reduce sensitization to milk proteins, as previously described with casein [10] in this GI phenotype of CM allergy. Yogurt enabled only partial avoidance of cow's milk products. Further reports should evaluate our intervention in order to design a successful protocol, as in other allergy phenotypes.

\section{Acknowledgments}

We would like to thank all the registered nurses and the laboratory technicians involved in this study. 


\section{Funding}

This study was funded by Unidad de Gestión AlergologíaNorte, Hospital del Tórax/Ofra.

\section{Conflicts of Interest}

The authors declare that they have no conflicts of interest.

\section{References}

1. Morita H, Nomura I, Matsuda A, Saito $H$, Matsumoto K. Gastrointestinal food allergy in infants. Allergol Int. 2013;62:297-307.

2. Poza P, Glez R, Barrios Y, Franco A, Matheu V. MIP-1alpha, MCP-1, and desensitization in anaphylaxis from cow's milk. N Eng J Med. 2012;367:282-4.

3. Martorell Calatayud C, Muriel García A, Martorell Aragonés A, De La Hoz Caballer B. Safety and efficacy profile and immunological changes associated with oral immunotherapy for IgE-mediated cow's milk allergy in children: systematic review and meta-analysis. J Investig Allergol Clin Immunol. 2014;24:298-307.

4. B Rodríguez Jiménez, J Domínguez Ortega, JM González García, C Kindelan Recarte Gastroenteritis Due to Allergy to Cow's Milk J Invest Allergol Clin Immunol. 2011;21:150-2.

5. Chehade M, Sampson HA. The role of lymphocytes in eosinophilic gastrointestinal disorders. Immunol Allergy Clin North Am. 2009;29:149-58, xii.

6. Sicherer SH. Clinical aspects of gastrointestinal food allergy in childhood. Pediatrics. 2003;111:1609-16.

7. Poza-Guedes P, Barrios Y, Sanchez-Machin I, Franco A, Gonzalez R, Matheu V. Role of specific IgE to $\beta$-lactoglobulin in the gastrointestinal phenotype of cow's milk allergy. Allergy Asthma Clin Immunol. 2016;12:7.

8. Kontopidis G, Holt C, Sawyer L. Invited review: betalactoglobulin: binding properties, structure, and function. J Dairy Sc. 2004;87:785-96.

9. Ehn BM, Ekstrand B, Bengtsson U, Ahlstedt S. Modification of $\mathrm{IgE}$ binding during heat processing of the cow's milk allergen beta-lactoglobulin. J Agricultural Food Chem 2004;52:1398403.

10. Cases B, García-Ara C, Boyano MT, Pérez-Gordo M, Pedrosa $M$, Vivanco F, Quirce $S$, Pastor-Vargas C. Phosphorylation reduces the allergenicity of cow casein in children with selective allergy to goat and sheep milk. J Investig Allergol Clin Immunol. 2011;21:398-400.

Manuscript received March 3, 2016; accepted for publication May 23, 2016.

Victor Matheu

Consulta de Alergia Infantil, Unidad de Alergología-Norte Hospital del Tórax/Ofra, CHUNSC 38320 San Cristóbal de La Laguna, Spain E-mail: Victor.Matheu@gmail.com

\section{Cross-reactivity in AED-Induced Severe Cutaneous Adverse Reaction: A Case Report}

Khor AHP ${ }^{1,2}, \operatorname{Lim~} \mathrm{KS}^{1 *}$, Tan $\mathrm{CT}^{1}, \mathrm{Kwan} \mathrm{Z}^{3}, \mathrm{Ng} \mathrm{CC}^{2}$

${ }^{1}$ Division of Neurology, Department of Medicine, Faculty of Medicine, University of Malaya, 50603 Kuala Lumpur, Malaysia ${ }^{2}$ Genetics and Molecular Biology Unit, Institute of Biological Sciences, Faculty of Science, University of Malaya, 50603 Kuala Lumpur, Malaysia

${ }^{3}$ Division of Dermatology, Department of Medicine, Faculty of Medicine, University of Malaya, 50603 Kuala Lumpur, Malaysia

J Investig Allergol Clin Immunol 2016; Vol. 26(5): 329-331 doi: $10.18176 /$ jiaci.0085

Key words: Antiepileptic drugs. Cross-reactivity. Stevens-Johnson syndrome. Toxic epidermal necrolysis. Hypersensitivity.

Palabras clave: Antiepilépticos. Reactividad cruzada. Síndrome de Stevens-Johnson. Necrolisis epidérmica tóxica. Hipersensibilidad.

Aromatic antiepileptic drugs (AEDs), in particular carbamazepine, phenytoin, phenobarbital, and lamotrigine, are some of the most common medications associated with severe cutaneous adverse reactions, such as Stevens-Johnson syndrome (SJS), toxic epidermal necrolysis (TEN), and drug reactions with eosinophilia and systemic syndrome (DRESS). The reported incidence of SJS/TEN is 1.2 cases per million inhabitants per year. Cross-reactivity between these aromatic antiepileptic drugs is not uncommon [1]. A large-scale study investigating risk predictors of AED-induced rash found that one of the strongest predictors is a history of rash with another AED [2]. This finding is supported by another study showing a significant association between carbamazepine-, phenytoin-, and oxcarbazepine-induced hypersensitivity skin reactions and a previous history of AED-induced rash [3]. However, to the best of our knowledge, there has only been 1 previous case report, without HLA genotype testing, of cross-reactivity in AED-induced severe cutaneous adverse reactions [4]. We report a case of SJS induced by lamotrigine after a history of carbamazepine-induced SJS, and provide information on HLA genotyping results.

A 63-year-old Indian woman with a diagnosis of rightsided trigeminal neuralgia since 2002 presented with facial pain described as sharp and piercing that lasted approximately 3 to 4 minutes and was aggravated by chewing and moving of the jaw. Magnetic resonance imaging of the brain did not reveal any masses or aberrant vessels compressing the trigeminal nerve roots.

Carbamazepine $200 \mathrm{mg} 3$ times a day was prescribed and resulted in complete pain relief. Fourteen days later, the patient developed a generalized rash on the trunk and limbs and was diagnosed with carbamazepine-induced SJS. The rash regressed over a month. The algorithm of drug causality for epidermal necrolysis (ALDEN) score was 6. (Table). The patient was put on sodium valproate $200 \mathrm{mg}$ twice a day but 
Table. ALDEN (Algorithm of Drug Causality for Epidermal Necrolysis) Scores for Patient

\begin{tabular}{|c|c|c|c|c|c|c|c|}
\hline Drug & $\begin{array}{l}\text { Delay From Initial } \\
\text { Drug Intake to Onset } \\
\text { of Reaction; Index } \\
\text { Day (Value) }\end{array}$ & $\begin{array}{l}\text { Drug Present in } \\
\text { Body on Index } \\
\text { Day (value) }\end{array}$ & $\begin{array}{l}\text { Prechallenge/ } \\
\text { Rechallenge } \\
\text { (Value) }\end{array}$ & $\begin{array}{l}\text { Dechallenge } \\
\text { (Value) }\end{array}$ & $\begin{array}{l}\text { Type } \\
\text { of Drug } \\
\text { (Notoriety) }\end{array}$ & $\begin{array}{l}\text { Other } \\
\text { Cause }\end{array}$ & $\begin{array}{l}\text { Final } \\
\text { Score }^{\mathrm{a}}\end{array}$ \\
\hline Carbamazepine & $14 \mathrm{~d}(+3)$ & $\begin{array}{l}\text { Drug withdrawn } \\
\text { on day of rash }(0)\end{array}$ & $\begin{array}{l}\text { No known } \\
\text { previous } \\
\text { exposure }(0)\end{array}$ & $\begin{array}{l}\text { Drug } \\
\text { stopped (0) }\end{array}$ & 3 & None & 6 \\
\hline Lamotrigine & $20 \mathrm{~d}(+3)$ & $\begin{array}{l}\text { Drug withdrawn } \\
\text { on day of rash }(0)\end{array}$ & $\begin{array}{l}\text { Previous } \\
\text { Stevens-Johnson } \\
\text { syndrome induced } \\
\text { by carbamazepine (2) }\end{array}$ & $\begin{array}{l}\text { Drug } \\
\text { stopped (0) }\end{array}$ & 3 & None & 8 \\
\hline
\end{tabular}

aFinal score: $<0$, very unlikely; $0-1$, unlikely; $2-3$, possible; $4-5$, probable; $\geq 6$, very probable.

the adverse effects were intolerable. This drug was substituted with gabapentin $300 \mathrm{mg}$ twice a day, to which baclofen $10 \mathrm{mg}$ 3 times a day was later added.

Ten years later, with increased pain intensity despite increased gabapentin dosage, which caused drowsiness, the patient was started on lamotrigine $25 \mathrm{mg}$ once a day for 1 week, titrated upwards at a rate of $25 \mathrm{mg}$ per week. On day 20, while on lamotrigine $100 \mathrm{mg}$ a day, she developed a second episode of SJS. The ALDEN score was 8 (Table). The patient was subsequently treated with pregabalin $300 \mathrm{mg}$ and amitriptyline $12.5 \mathrm{mg}$ daily and experienced no adverse effects.

HLA-A and B allele genotyping detected HLA-A*02:11 and $A * 24: 17$ and HLA-B*40:06 and $B * 51: 06$. These alleles have not been reported in association with AED-induced SJS/ TEN.

Assessment of causality between the severe cutaneous adverse reaction and the AED was based on ALDEN scores, which, at 6 and higher, supported the causal relationship between the AEDs and SJS.

To our knowledge, cross-reactivity in AED-induced severe cutaneous adverse reactions, such as SJS, has only been reported once in the literature, by Aouam et al [4]. The causal relationship between carbamazepine and lamotrigine and the reaction reported in that case was confirmed with positive skin patch tests at the 48 -hour reading. Patch tests were not performed in our case and the causality assessment was based only on ALDEN scores.

Although the incidence is low, there have been reports of cross-reactivity between AEDs and tricyclic antidepressants [5]. Seitz et al [6] observed recurrence of hypersensitivity syndrome in 5 of 36 patients on tricyclic antidepressants with a prior history of hypersensitivity to AEDs. The authors did not observe cross-reactivity between amitriptyline and aromatic AEDs, but caution should be taken when prescribing tricyclic antidepressants to patients with a prior history of hypersensitivity to aromatic AEDs.

Recent studies have reported an association between carbamazepine-induced SJS/TEN and the HLA-B*15:02 allele in populations from Southeast Asia [7,8]. A similar association was subsequently reported for phenytoin- and lamotrigineinduced SJS [7,9]. The findings of a large meta-analysis further implicated HLA-A*31:01 in SJS and generalized rash [10]. Neither of these alleles were detected in our patient.
Negative results for known HLA-alleles associated with AED-induced severe cutaneous adverse drug reactions, such as in our case, does not predict against cross-reactivity. Although these reactions are unpredictable, identification of predisposing risk factors prior to drug selection can reduce the probability of a hypersensitivity reaction. Patients with a history of severe cutaneous adverse reactions to aromatic AEDs such as carbamazepine, phenobarbital, phenytoin, and lamotrigine are best managed with newer AEDs with a lower risk of severe cutaneous adverse reactions.

This case showed cross-reactivity in aromatic AEDs that induced a severe cutaneous adverse drug reaction. Although HLA-genotyping helps to predict reactions, caution should be taken when prescribing alternative AEDs to patients with a previous history of AED-induced severe cutaneous adverse drug reactions, despite negative results for known HLA-alleles.

\section{Funding}

This study is funded by University of Malaya under High Impact Research Grant from the Ministry of Higher Education research fund (reference no.: M.C/625/1/1HIR/MOHE/ CHAN-02 [H-50001-A000023]) and Postgraduate Research Fund (grant no.: PG112-2015B).

\section{Conflicts of Interest}

The authors declare that they have no conflicts of interest.

\section{References}

1. Hirsch LJ, Arif H, Nahm EA, Buchsbaum R, Resor SR Jr, Bazil CW. Cross-sensitivity of skin rashes with antiepileptic drug use. Neurology. 2008;71(19):1527-34.

2. Arif $H$, Buchsbaum $R$, Weintraub $D$, Koyfman S, SalasHumara C, Bazil CW, Resor SR Jr, Hirsch LJ. Comparison and predictors of rash associated with 15 antiepileptic drugs. Neurology. 2007;68(20):1701-9.

3. Alvestad S, Lydersen S, Brodtkorb E. Cross-reactivity pattern of rash from current aromatic antiepileptic drugs. Epilepsy Res. 2008;80(2-3):194-200.

4. Aouam K, Ben Romdhane F, Loussaief C, Salem R, Toumi A, Belhadjali H, Chaabane A, Boughattas NA, Chakroun 
M. Hypersensitivity syndrome induced by anticonvulsants: possible cross-reactivity between carbamazepine and lamotrigine. J Clin Pharmacol. 2009;49 (12):1488-91.

5. Gaig $P$, Garcia-Ortega $P$, Baltasar M, Bartra J. Drug neosensitization during anticonvulsant hypersensitivity syndrome. J Investig Allergol Clin Immunol. 2006;16(5):3216.

6. Seitz CS, Pfeuffer $P$, Raith $P$, Brocker EB, Trautmann A. Anticonvulsant hypersensitivity syndrome: cross-reactivity with tricyclic antidepressant agents. Ann Allergy Asthma Immunol. 2006;97(5):698-702.

7. Locharernkul C, Loplumlert J, Limotai C, Korkij W, Desudchit T, Tongkobpetch S, Kangwanshiratada O, Hirankarn N, Suphapeetiporn K. Carbamazepine and phenytoin induced Stevens-Johnson syndrome is associated with HLA-B*1502 allele in Thai population. Epilepsia. 2008;49(12):2087-91.

8. Wu XT, Hu FY, An DM, Yan B, Jiang X, Kwan P, Stefan H, Zhou D. Association between carbamazepine-induced cutaneous adverse drug reactions and the HLA-B ${ }^{*} 1502$ allele among patients in central China. Epilepsy Behav. 2010;19(3):405-8.

9. Cheung YK, Cheng SH, Chan EJ, Lo SV, Ng MH, Kwan P. HLA-B alleles associated with severe cutaneous reactions to antiepileptic drugs in Han Chinese. Epilepsia. 2013;54(7):1307-14.

10. Genin $E$, Chen DP, Hung SI, Sekula $P$, Schumacher $M$, Chang PY, Tsai SH, Wu TL, Bellón T, Tamouza R, Fortier C, Toubert A, Charron D, Hovnanian A, Wolkenstein P, Chung WH, Mockenhaupt $M$, Roujeau JC. HLA-A*31:01 and different types of carbamazepine-induced severe cutaneous adverse reactions: an international study and meta-analysis. Pharmacogenomics J. 2014;14(3):281-8.

Manuscript received April 5, 2016; accepted for publication, June 1, 2016.

\section{Vitiligo Induced by Specific Immunotherapy With Grass Pollen: The Koebner Phenomenon}

Rodríguez-Jiménez $\mathrm{B}^{1}$, Muñoz-García $\mathrm{E}^{1}$, Veza Perdomo $\mathrm{S}^{1}$, González Herrada $\mathrm{C}^{2}$, Kindelán-Recarte $\mathrm{C}^{1}$, Domínguez-Ortega $\mathrm{J}^{3}$ ${ }^{1}$ Allergy Unit, Hospital Universitario de Getafe, Madrid, Spain ${ }^{2}$ Dermatology Service, Hospital Universitario de Getafe, Madrid, Spain

${ }^{3}$ Department of Allergy, Hospital La Paz Institute for Health Research (IdiPAZ), Madrid, Spain; CIBER de Enfermedades Respiratorias (Ciberes)

J Investig Allergol Clin Immunol 2016; Vol. 26(5): 331-332 doi: $10.18176 /$ jiaci.0088

Key words: Grass pollen. Koebner phenomenon. Specific immunotherapy. Vitiligo.

Palabras clave: Polen de gramíneas. Fenómeno de Koebner. Inmunoterapia específica. Vitíligo.

Vitiligo is an autoimmune disease of unknown origin that affects approximately $1 \%$ of the world's population. It is characterized by local or generalized depigmentation of the skin and/or mucosal membranes [1]. One of the features that may help predict the course of disease and response to treatment is the Koebner phenomenon (KP), also known as the isomorphic response, which represents a basic principle in dermatology. This phenomenon was originally described by the German dermatologist, Heinrich Koebner, who observed the appearance of psoriasis lesions in areas of healthy skin in patients with psoriasis following local trauma, such as excoriations, tattoos, and horse bites [2]. The phenomenon has since been described in relation to other disorders such as vitiligo and lichen planus (true koebnerization) [3]. These posttraumatic lesions are clinically and histologically similar to those of the underlying disease. A recently developed method for the evaluation and classification of KP takes into account different factors such as the patient's clinical history (type $1 \mathrm{KP}$ ), physical examination findings (type $2 \mathrm{KP}$ ), and experimental induction of skin lesions (type $3 \mathrm{KP}$ ) [4]. Vitiligo has been shown to progress differently in the presence of KP, regardless of type, with a larger affected body surface, greater disease activity in the preceding 12 months, and a poorer response to treatment [1].

We present the case of a 42-year-old man, without autoimmune diseases or any other history of interest, who had been undergoing follow-up in the allergology unit since 2007 due to respiratory allergic disease (rhinoconjunctivitis and moderate persistent asthma secondary to grass pollen allergy) and oral allergy to fruits associated with profilin. The allergy study showed positive skin prick tests for grasses, Cynodon dactylon, olive, Platanus acerifolia, Chenopodium album, birch, ash tree, and profilin (ALK, Abelló, Madrid, Spain). Specific IgE (ImmunoCAP, Thermo Fisher) was determined for grasses $(72.40 \mathrm{kU} / \mathrm{L})$, olive $(4.18 \mathrm{kU} / \mathrm{L})$, 
and the recombinant allergens of Phleum pratense: $\mathrm{rPhl} \mathrm{p} 1$ (18.20 kU/L), rPhl p 5 (62.40 kU/L), rPhl p 7 (polcalcin), and rPhl p 12 (Phleum p profilin) $(6.50 \mathrm{kU} / \mathrm{L})$.

Based on the above findings, the patient received specific allergen immunotherapy (AIT) via the subcutaneous route with Depigoid 100\% Grasses group (Dactylis glomerata, Festuca pratensis, Lolium perenne, Phleum pratense, Poa pratensis) (Leti, Barcelona, Spain) administered perennially on a monthly basis for 4 years (2008-2012). The therapy resulted in an improvement in respiratory symptoms. The patient showed good tolerance of AIT over the 4 years of treatment, with no early or late local or systemic reactions. Two years after completion of the treatment, the patient was reviewed at our unit and explained that approximately 1 year after the end of AIT he started to develop hypopigmented point lesions on both arms, coinciding with the vaccine dose administration site (Figure). The lesions were more numerous on the right arm, where they merged to form larger hypopigmented areas. The patient explained that the treatment had been administered more often in the right arm, since he had undergone surgery of the left arm and preferred to be injected as little as possible in that arm. There were no other similar lesions elsewhere on the body.

The patient was evaluated in the dermatology department, where he was diagnosed with vitiligo and prescribed topical $0.1 \%$ tacrolimus; there had been no repigmentation of the lesions by the time we saw him at our unit. He refused the option of a biopsy because he did not want any more lesions on his arms.

The patient had not been previously diagnosed with vitiligo and had no past history of skin lesions. However, KP has been related to lesions in areas exposed to trauma in patients with no pre-existing dermatosis [5]. None of the patient's relatives had vitiligo, but his father and his grandmother had been diagnosed with rheumatoid arthritis. The literature cites a number of triggering factors for KP, including physical trauma, burns, insect bites, surgical incisions, allergic and irritating reactions, radiation exposure, needle acupuncture, and tattoos [5-7].

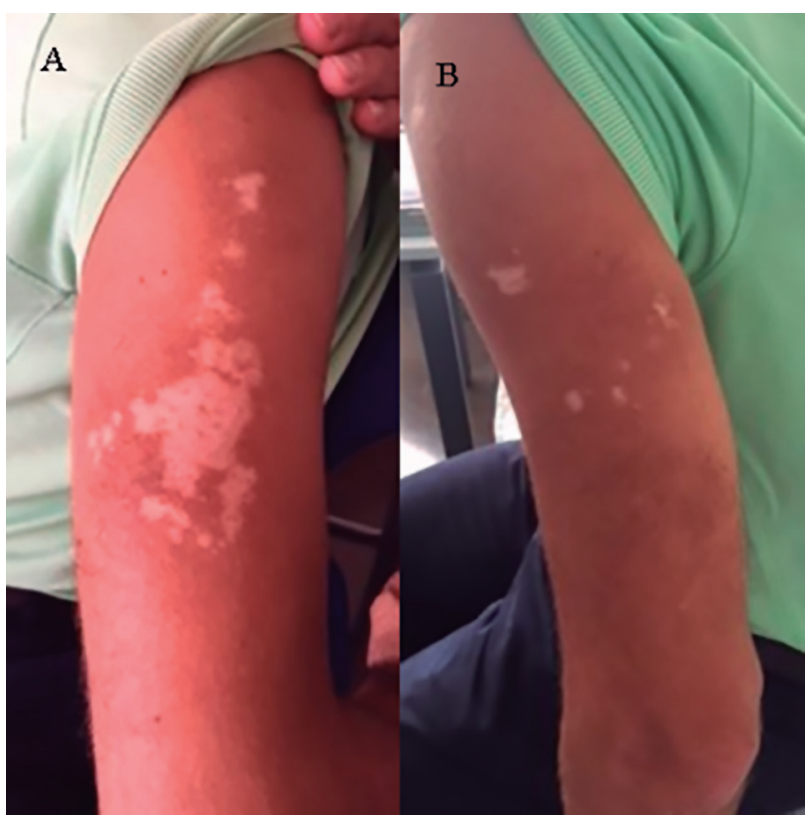

Figure. A, Right arm. B, Left arm.
We have described the case of a patient who started to develop hypopigmented skin lesions 1 year after the end of subcutaneous AIT with grasses, administered on a monthly basis over 4 years. Although the period between skin trauma and the appearance of KP lesions is generally short (10-20 days), the reported latency ranges from 3 days to 2 years [5]. The etiopathogenesis of KP in vitiligo remains unclear, though immune, neural, and vascular factors have been suggested to play an important role [4]. In our case it is difficult to establish whether the triggering cause of KP was repeated trauma due to the needle, as has been described in cases of psoriasis induced by acupuncture [7], or the immune response to administration of the grass extract. To our knowledge, this is the first case of vitiligo associated with KP following the administration of subcutaneous AIT with grass pollen. The possibility of such phenomena in patients who develop vitiligo after a cycle of AIT should be taken into account.

\section{Funding}

The authors declare that no funding was received for the present study.

\section{Conflicts of Interest}

The authors declare that they have no conflicts of interest.

\section{References}

1. van Geel N, Speeckaert R, De Wolf J, Bracke S, Chevolet I, Brochez L, Lambert J. Clinical significance of Koebner phenomenon in vitiligo. Br J Dermatol. 2012;167:1017-24.

2. Koebner H. Zur Aetiologie der Psoriasis. Vjschr Dermatol. 1876;3:559.

3. Boyd AS, Neldner KH. The isomorphic response of Koebner. Int J Dermatol. 1990; 29:401-10.

4. van Geel N, Speeckaert $R$, Taieb A, Picardo $M$, Böhm $M_{\text {, }}$ Gawkrodger DJ, Schallreuter K, Bennett DC, van der Veen W, Whitton M,Moretti S, Westerhof W, Ezzedine K, Gauthier Y; VETF members. Koebner's phenomenon in vitiligo: European position paper. Pigment Cell Melanoma Res. 2011;24:564-73.

5. Weiss G, Shemer A, Trau H. The Koebner phenomenon: review of the literature. J Eur Acad Dermatol Venereol. 2002;16: 241-8.

6. Orzan OA, Popa LG, Vexler ES, Olaru I, Voiculescu VM, Bumbăcea RS. Tattoo-induced psoriasis.J Med Life. 2014;7:65-8.

7. Zhu LL, Hong Y, Zhang L, Huo W, Zhang L, Chen HD, Gao $\mathrm{XH}$. Needle acupuncture-induced Koebner phenomenon in a psoriatic patient. J Altern Complement Med. 2011;17 (12):1097-8.

Manuscript received March 17, 2016; accepted for publication, June 10, 2016 


\section{Resolution of Common Variable Immunodeficiency After HIV Infection}

Balugo-López V, Hernández García de la Barrera E, Sastre J Allergy Service, Fundación Jiménez Díaz and Universidad Autónoma de Madrid, Madrid, Spain

J Investig Allergol Clin Immunol 2016; Vol. 26(5): 333-334 doi: $10.18176 /$ jiaci.0090

Key words: Common variable immunodeficiency. HIV infection. Hypogammaglobulinemia.

Palabras clave: Inmunodeficiencia común variable. Infección VIH. Hipogammaglobulinemia.

Common variable immunodeficiency (CVID) is the most common of the primary immunodeficiency disorders requiring immunoglobulin replacement, and affects about 1 in every 25000 white people. The characteristic feature is severe hypogammaglobulinemia, predominantly affecting the $\mathrm{IgG}$ and IgA classes. The majority of patients present with recurrent infections, mostly affecting the respiratory tract, although gastrointestinal infections are also common $[1,2]$. The mechanisms underlying CVID are not known, though evidence points to many different genetic defects inducing abnormalities in B and T lymphocytes [1,3]. Autoimmune diseases and malignancies may also complicate the course of the disease, which is usually favorable with immunoglobulin replacement therapy.

In rare cases, CVID has been reported to resolve transiently or permanently with human immunodeficiency virus (HIV) infection [4-7].

We present the case of a 21-year-old male ex-smoker with a history of repeat sinusitis since childhood. In March 2009 he presented to our allergy service with complaints of dry cough and dyspnea of a few weeks' duration. A physical examination produced no abnormal findings. Skin tests to common inhalants were negative. Spirometry and fraction of exhaled nitric oxide were within normal values. A chest x-ray demonstrated no alterations. A complete blood count showed $5.9 \%$ eosinophils, and an analysis of biochemical data revealed no abnormalities.

Immunoglobulin determinations showed a decrease in IgG and $\operatorname{IgM}$ and undetectable levels of $\operatorname{IgA}$ and $\operatorname{IgE}$ (values in $\mathrm{mg} / \mathrm{dL}$ : IgG, 284; IgA, 0; IgM, 22). Immunophenotyping showed $8 \%$ of B lymphocytes and $58 \%$ of $\mathrm{T}$ lymphocytes and an inverted CD4/CD8 ratio $(748 / 2006$ cells/ $\mu \mathrm{L})$. The patient was diagnosed with CVID (SmB+ EUROclass) [8] and began treatment with intravenous human immunoglobulin (IVIG) at a dose of $200 \mathrm{mg} / \mathrm{kg}$ once every 3 weeks. Monthly immunoglobulin quantification was performed in order to adjust the treatment and maintain levels of $\mathrm{IgG}$ above $500 \mathrm{mg} / \mathrm{dL}$ (Figure).

During follow-up, the patient experienced recurrent episodes of urethritis due to his sexual behavior, although

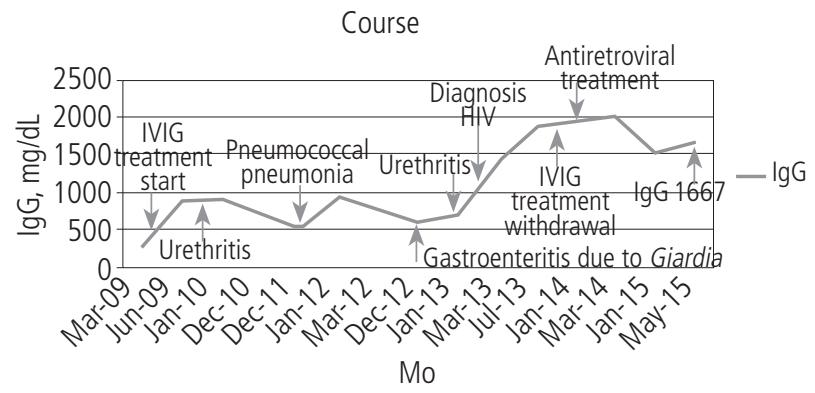

Figure. Clinical course and changes in serum IgG levels in patient. IVIG indicates intravenous immunoglobulin.

in all cases serology tests for sexually transmitted diseases, including HIV, were negative. In 2012, the patient was admitted to the hospital on 2 occasions, the first time for a respiratory infection induced by Streptococcus pneumoniae, and the second for a gastrointestinal infection due to Giardia lamblia. Both infections coincided with a decrease in IgG levels despite treatment with gamma globulin.

After a new episode of urethritis in June 2013, the patient was diagnosed with HIV infection (positive HIV-1 antibodies and a positive Western blot for gp120,gp41, p31, p24, and p17 from HIV), surprisingly coinciding with an unexpected increase in levels of $\operatorname{IgG}(>1500 \mathrm{mg} / \mathrm{dL})$. HIV viral load in serum was undetectable.

Over the next 6 months the patient's levels of $\mathrm{IgG}$ remained high despite monthly IVIG infusions; the infusions were discontinued in December 2013. Antiretroviral treatment was started in spite of an undetectable HIV viral load. Two years later, the patient still has high levels of IgG but very low levels of $\operatorname{IgA}$ (IgG, 1747; IgM, 264; IgA, 2; and IgE, 24). The most recent immunophenotypic study revealed normal total lymphocyte count with a correct distribution of natural killer cells and $\mathrm{B}$ and $\mathrm{T}$ lymphocytes. The CD4/CD8 ratio $(676 / 1536$ cells $/ \mu \mathrm{L})$ was inverted, though the CD4 count remained normal. The level of B lymphocytes was normal, and the proportion of virgin B cells and different types of memory B cells were also within normal range. We observed a correct distribution of immunoglobulin free light chains, and no antigenic data suggested peripheral expression of a monoclonal lymphoproliferative disorder. CD28 and CD27 (lymphoplasmocytoid cells) cells were in normal proportion. No new, relevant infections were reported during this 2-year period (Figure).

This case shows the association of HIV infection and development of hypergammaglobulinemia and recovery of IgG production in a patient with CVID over at least 2 years of follow-up, and adds further evidence to the few similar cases reported in the literature [4-7.]

As in similar reported cases, our patient has shown recovery of $\operatorname{IgG}, \operatorname{IgM}$, and $\operatorname{IgE}$ while $\operatorname{IgA}$ levels remain undetectable. This finding is compatible with the notion that specific genetic - and possibly environmental-factors are required to induce CVID in the context of IgA deficiency [9] .

Hypergammaglobulinemia is a common finding in the early stages of HIV infection due to polyclonal B-cell activation, which could explain the course of these cases [10]. 
Treatment with antiretroviral drugs does not appear to affect this B-cell activation, since both in our case and in the report by Jolles et al [4], immunoglobulin recovery was maintained in spite of antiretroviral therapy. Nevertheless, the cause behind immunoglobulin recovery in these cases remains unanswered.

\section{Acknowledgments}

Oliver Shaw for editorial assistance.

\section{Funding}

The authors declare that no funding was received for the present study.

\section{Conflicts of Interest}

VBL and EHGB declare they have no conflicts of interest. JS reports having served as a consultant to Thermo Fisher Scientific, Schering-Plough, Merck, FAES Farma, Novartis, Roche, Sanofi, Gennetech, and GSK; having been paid lecture fees by Novartis, GSK, Stallergenes, FAES FARMA, and $\mathrm{UCB}$; and having received grant support from Thermo Fisher, GSK, and ALK-Abelló.

\section{References}

1. Bonilla FA, Barlan I, Chapel $H$, Costa-Carvalho BT,

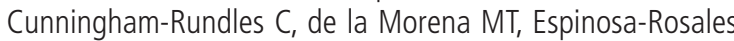
FJ, Hammarström L, Nonoyama S, Quinti I, Routes JM, Tang ML, Warnatz K. International Consensus Document (ICON): Common Variable Immunodeficiency disorders. J Allergy Clin Immunol Pract. 2016 Jan-Feb;4(1):38-59

2. Karakoc-Aydiner $\mathrm{E}$, Ozen AO, Baris S, Ercan H, Ozdemir C, Barlan IB. Alteration in humoral immunity is common among family members of patients with common variable immunodeficiency. J Investig Allergol Clin Immunol. 2014;24(5):346-51

3. Abolhassani H, Cheraghi T, Rezaei N, Aghamohammadi A, Hammarström L. Common Variable Immunodeficiency or LateOnset Combined Immunodeficiency: A New Hypomorphic JAK3 Patient and Review of the Literature. J Investig Allergol Clin Immunol. 2015;25(3):218-20

4. Jolles S, Tyrer M, Johnson M, Webster D. Long term recovery of $\lg \mathrm{G}$ and IgM production during HIV infection in a patient with common variable immunodeficiency (CVID). J Clin Pathol. 2001;Sep;54(9):713-5.

5. Morell A, Barandun S, Locher G. HTLV-III seroconversion in a homosexual patient with common variable immunodeficiency. N Engl J Med. 1986;Aug 14;315(7):456-57.

6. Webster AD, Lever A, Spickett G, Beattie R, North M, Thorpe R. I. Recovery of antibody production after HIV infection in "common" variable hypogammaglobulinaemia. Clin Exp Immunol. 1989;77:309-13.

7. Wright JJ, Birx DL, Wagner DK, Waldmann TA, Blaese RM, Fleisher TA. Normalization of antibody responsiveness in a patient with common variable hypogammaglobulinemia and HIV infection. N Engl J Med. 1987;317:1516-20

8. Wehr C, Kivioja T, Schmitt C, Ferry B, Witte T, Eren E, VIkova M, Hernandez M, Detkova D, Bos PR, Poerksen G, von Bernuth
H, Baumann U, Goldacker S, Gutenberger S, Schlesier M, Bergeron-van der Cruyssen $F$, Le Garff $M$, Debré $P$, Jacobs $R$, Jones J, Bateman E, Litzman J, van Hagen PM, Plebani A, Schmidt RE, Thon V, Quinti I, Espanol T, Webster AD, Chapel $H$, Vihinen $M$, Oksenhendler $E$, Peter $H H$, Warnatz K. The EUROclass trial: defining subgroups in common variable immunodeficiency. Blood. 2008;1;111(1):77-85

9. Vorechovsk I,Webster AD, Plebani A, Hammarström L. Genetic linkage of $\lg A$ deficiency to the major histocompatibility complex: evidence for allele segregation distortion, parentof-origin penetrance differences, and the role of anti-lgA antibodies in disease predisposition. Am J Hum Genet. 1999;64:1096-109.

10. Moir S, Fauci AS. B cells in HIV infection and disease. Nat Rev Immunol. 2009;9: 235-45

Manuscript received February 22, 2016; accepted for publication, June 17, 2016.

Joaquín Sastre Servicio de Alergología Fundación Jiménez Díaz Av. Reyes Católicos 2 28040 Madrid Spain

E-mail: jsastre@fjd.es 


\section{Kounis Syndrome After Levofloxacin Intake: A Clinical Report and Cross-reactivity Study}

García Núñez I I,2, Algaba Mármol MA³ , Barasona Villarejo $\mathrm{MJ}^{4}$, Suárez Vergara $\mathrm{M}^{2}$, Espínola González $\mathrm{F}^{5}$, Reina Ariza E ${ }^{1}$ ${ }^{1}$ Allergy Department, Hospital Quirón Málaga, Malaga, Spain ${ }^{2}$ Allergy Department, Hospital Quirón Campo de Gibraltar, Cádiz, Spain

${ }^{3}$ DCCU Écija, Osuna Primary Care Unit, Osuna, Seville, Spain

${ }^{4}$ Allergy Department, Hospital Universitario Reina Sofía, Cordoba, Spain

${ }^{5}$ Faculty of Medicine; Malaga University, Malaga, Spain

J Investig Allergol Clin Immunol 2016; Vol. 26(5): 335-336 doi: 10.18176/jiaci.0091

Key words: Kounis syndrome. Levofloxacin. Ciprofloxacin. Basophil activation test. Specific $\lg \mathrm{E}$.

Palabras clave: Síndrome Kounis. Levofloxacino. Ciprofloxacino. Test activación basófilos. IgE específica.

Kounis and Zavras [1] described a case of histamineinduced coronary artery spasm in 1991 and this concurrence of an acute coronary event with an acute allergic reaction (anaphylactic or anaphylactoid) is now known as Kounis syndrome. It is due to extensive vasodilatation and low cardiac output. In the last 20 years, numerous factors have been implicated in Kounis syndrome, including drugs (eg, $\beta$-lactams [2], ibuprofen [3], contrast media), hymenoptera stings, and food.

We describe the case of a 35 year-old man who presented at our allergy department with clinical symptoms (acute coronary syndrome and generalized angioedema with urticaria) and ST decline in several leads in an emergency electrocardiogram performed 30 minutes after the first intake of levofloxacin, which had been prescribed to treat sinusitis. The cardiac evaluation (coronary angiography, cardiac catheterization, plus an exercise stress test) showed normal results. The findings were compatible with a diagnosis of Kounis syndrome. After ruling out all other possible causes, and after obtaining the patient's informed signed consent, we performed a prick test $(5 \mathrm{mg} / \mathrm{mL})$ and intradermal test $(0.005 \mathrm{mg} / \mathrm{mL}$ and $0.05 \mathrm{mg} / \mathrm{mL})$ with levofloxacin. Additional tests included a basophil activation test (BAT) with BasoTest (BD Biosciences), specific IgE to quinolones, and a drug provocation test (DPT) with an alternative drug from the same family.

The prick and intradermal tests were negative in our patient, but positive in 2 patients from a control group of 10 patients with good tolerance of levofloxacin, ciprofloxacin, and ofloxacin. The BAT, performed according to the manufacturer's instructions, showed a positive result for levofloxacin $(4.5 \%)$ and a negative result for ciprofloxacin and ofloxacin. All the patients in the control group had negative BAT results. Specific IgE (ImmunoCAP, Thermo Fisher Scientific) was negative to ciprofloxacin and positive to levofloxacin $(0.67 \mathrm{kU} / \mathrm{L})$; the results in the control group were again negative. With these results, we performed a DPT with ciprofloxacin (placebo-placebo-50-100-100-250 mg) to identify an alternative treatment. The results were negative at the immediate and delayed readings ( 2 and 48 hours, respectively).

Three types of Kounis syndrome are now recognized [4]: type I, occurring in patients with normal cardiac findings (normal arteriography); type II, occurring in patients with pathological cardiac findings (atherosclerosis in arteriography); and type III, occurring in patients with the type II variant and previous heart problems. Our patient, a healthy man who experienced severe heart failure after levofloxacin intake, was diagnosed with type I Kounis syndrome. This is very important as the fact that no other clinical reasons can explain the symptoms experienced by the patient demonstrates that the drug was the trigger.

To our knowledge, this is the first clinical report of Kounis syndrome due to levofloxacin with a positive in vitro study. As mentioned, several drugs have been implicated in this syndrome, but there has only been 1 report involving a quinolone (ciprofloxacin) [5].

Kounis syndrome is challenging, as few cases are reported annually [6] and there are no established clinical protocols for confirming or excluding a diagnosis, which is established on clinical grounds. Accordingly, the clinical report is the main tool for confirming diagnosis, and it is therefore necessary to focus on ruling out other allergic and nonallergic causes. According to several authors, once the culprit drug has been identified in a patient diagnosed with Kounis syndrome, all other drugs in the same family must be avoided [7]. However, in vitro studies could have an important role in identifying an alternative to recommend to patients: BAT and/or specific $\mathrm{IgE}$ are used to confirm a diagnosis and search for alternative treatments, although published results show that an in vitro study cannot rule out hypersensitivity (low sensitivity and/or specificity of the studies) and must be confirmed by a DPT.

In our patient, the results of the in vivo studies for levofloxacin were unclear, as they were negative in our patient but positive in 2 of the control patients. Contradictory results regarding the sensitivity of skin tests in quinolone allergy have been reported, and positive skin tests in controls have been attributed to direct mast cell activation [8]. These conflicting reports led to the proposal for the use of low nonirritating intradermal test concentrations for quinolones, but these have low sensitivity. Based on the positive specific IgE and BAT results for levofloxacin and the negative results for ciprofloxacin, we advised our patient to undergo a DPT with the alternative drug ciprofloxacin, as low cross-reactivity has been reported between ciprofloxacin and levofloxacin $[9,10]$.

Few publications have reported cross-reactivity between quinolones $[7,9,10]$. In addition, few patients have been studied and the results have been very different (and contradictory). The results show that cross-reactivity between quinolones is unclear and that there are no general rules for predicting crossreactivity, which should be analyzed on a case-by-case basis.

To conclude, to the best of our knowledge this is the first report of Kounis syndrome due to levofloxacin with a positive in vitro study and tolerance of ciprofloxacin. 


\section{Funding}

The authors declare that no funding was received for the present study.

\section{Conflicts of Interest}

The authors declare that they have no conflicts of interest.

\section{References}

1. Kounis NG, Zavras GM. Histamine-induced coronary artery spasm: the concept of allergic angina. Br J Clin Pract. 1991 Summer;45(2):121-8

2. Ralapanawa DM, Kularatne SA. Kounis syndrome secondary to amoxicillin/clavulanic acid administration: a case report and review of literature. BMC Res Notes. 2015 Mar 26;8:97.

3. Alves MF, Pitta Mda L, Peres M, Leal M, Almeida AG, Ferreira da Silva G. Cardiac apical aneurysm secondary to ibuprofeninduced type 1-Kounis syndrome. Int J Cardiol. 2012 Jul 12;158(2):e41-3.

4. Biteker M. A new classification of Kounis syndrome Int J Cardiol. 2010 Dec 3;145(3):553.

5. Almpanis G, Siahos S, Karogiannis NC, Mazarakis A, Niarchos C, Kounis GN, Kounis NG. Kounis syndrome: two extraordinary cases. Int J Cardiol. 2011 Mar 3;147(2):e35-8.

6. Renda F, Landoni G, Trotta F, Piras D, Finco G, Felicetti $P_{1}$ Pimpinella G, Pani L. Kounis Syndrome: An analysis of spontaneous reports from international pharmacovigilance database. Int J Cardiol. 2015 Oct 22;203:217-220.

7. González I, Lobera T, Blasco A, del Pozo MD. Immediate hypersensitivity to quinolones: moxifloxacin cross-reactivity. J Investig Allergol Clin Immunol. 2005;15(2):146-9.

8. Campi P, Manfredi M, Severino M. IgE-mediated allergy to pyrazolones, quinolones and other non beta-lactam antibiotics. In: Pichler WJ, editor. Drug hypersensitivity. Basel: Karger Medical and Scientific Publishers; 2007. p. 216-32.

9. Chang B, Knowles SR, Weber E. Immediate hypersensitivity to moxifloxacin with tolerance to ciprofloxacin: report of three cases and review of the literature. Ann Pharmacother. 2010;44:740-5.

10. Lobera T, Audícana MT, Alarcón E, Longo N, Navarro B, Muñoz D. Allergy to quinolones: low cross-reactivity to levofloxacin. J Investig Allergol Clin Immunol. 2010;20(7):607-11.

- Manuscript received December 31, 2015; accepted for publication, June 17, 2016

Ignacio García Núñez

Allergy Department

Hospital Quiron Malaga

Avda Imperio Argentina $n^{\circ} 1$

29004 Malaga (Spain)

E-mail: h62ganui@hotmail.com

\section{Therapeutic Potential of Zoledronate-Activated Autologous $\gamma \delta \mathrm{T}$ Cells in Atopic Dermatitis}

\author{
Kamigaki T, Naitoh K, Goto S \\ Seta Clinic, Tokyo, Japan
}

J Investig Allergol Clin Immunol 2016; Vol. 26(5): 336-338 doi: 10.18176/jiaci.0092

Key words: $\gamma \delta \mathrm{T}$ cells. $V \gamma 9 \gamma \delta \mathrm{T}$ cells. Atopic dermatitis. TARC.

Palabras clave: Células T gamma/delta. Células T V gamma 9 gamma/ delta. Dermatitis atópica. Quimiocina regulada y activada del timo (TARC).

Current research on treatment of atopic dermatitis (AD) focuses on creating biological antagonists of the $\mathrm{T}_{\mathrm{H}} 2$ cytokine pathway, such as anti-interleukin (IL)-4 receptor $\alpha$ antibody, or finding drug candidates that repair epidermal barrier function $[1,2]$. In clinical trials, repeated intravenous injections of $\gamma \delta \mathrm{T}$ cells proved feasible and safe for the treatment of patients with malignancies [3]. We demonstrated that zoledronate-activated $\gamma \delta \mathrm{T}$ cells increase the frequency of $\mathrm{V} \gamma 9 \gamma \delta \mathrm{T}$ cells and produce mainly $\mathrm{T}_{\mathrm{H}} 1$ cytokines but not IL-17 [4]. In cell-based therapy in allergy patients, the use of $\mathrm{T}_{\mathrm{H}} 1$-polarized innate cells for establishing robust allergenspecific tolerance is clearly different from that of regulatory T cells (Tregs) or syngeneic hematopoietic stem cells [5,6]. In this study, we evaluated the safety and clinical outcomes of $\gamma \delta \mathrm{T}$ cell therapy in AD patients who received a single intravenous injection of zoledronate-activated $\gamma \delta \mathrm{T}$ cells.

The trial was approved by the Research Ethics Committee of Seta Clinic on February 2, 2012 (approval number: SCG12063). The primary endpoint was the safety of $\gamma \delta$ T cell therapy; the secondary endpoints were clinical outcome and immunological status. The study population comprised 5 male $\mathrm{AD}$ patients ( 3 with moderate $\mathrm{AD}$ and 2 with severe $\mathrm{AD}$ ), and the median age was 32 years (range, 31-34 years). Peripheral blood mononuclear cells (PBMCs) were collected from the whole blood of each patient and cultured with zoledronate, IL-2, and autologous serum for 14 days. Cell preparations were examined for the presence of bacteria and endotoxins, as previously reported $[3,4]$. A single intravenous injection of the ex vivo-expanded $\gamma \delta \mathrm{T}$ cells activated by zoledronate was administered to each patient. The use of topical medications was allowed, but the use of systemic corticosteroids and unapproved medicines was prohibited. For assessment of the primary endpoints, adverse events were monitored according to the Common Terminology Criteria of Adverse Events v4.0. The severity and extent of AD were assessed using the AD severity classification of the Japanese Dermatological Association (simple method, maximum 20 points) [7]. The secondary endpoint was the immunological status of the patients, who received a single intravenous injection of zoledronate-activated $\gamma \delta$ T cells. This was also monitored by flow cytometry of peripheral blood before injection and 1, 2, 4 , and 6 months after injection. Levels of the $\mathrm{T}_{\mathrm{H}} 2$ biomarker 

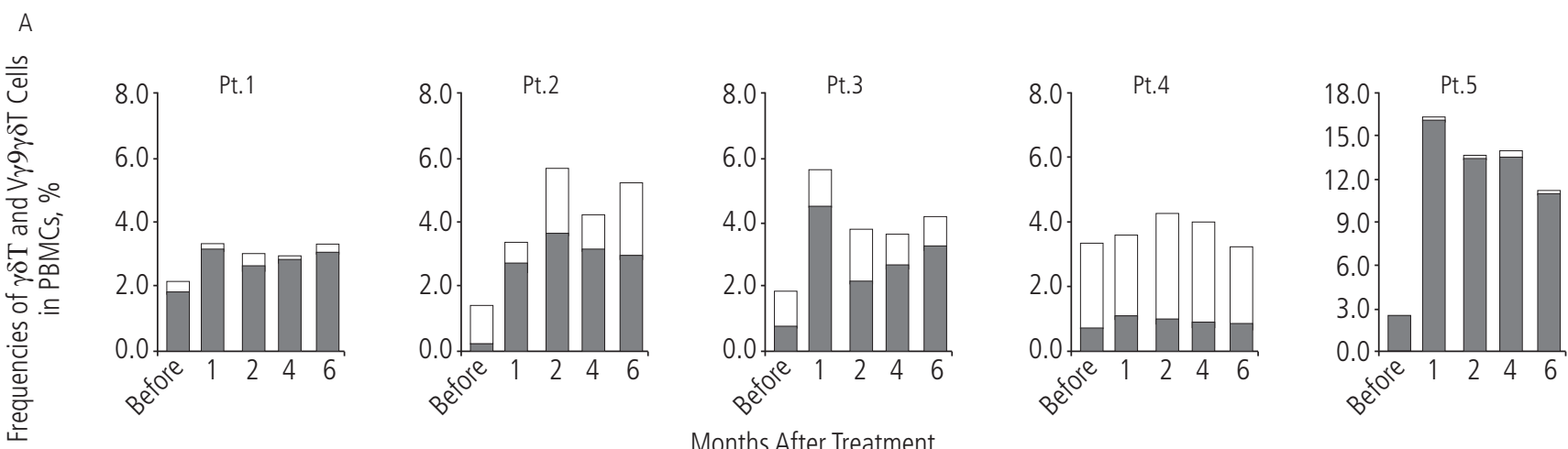

Months After Treatment

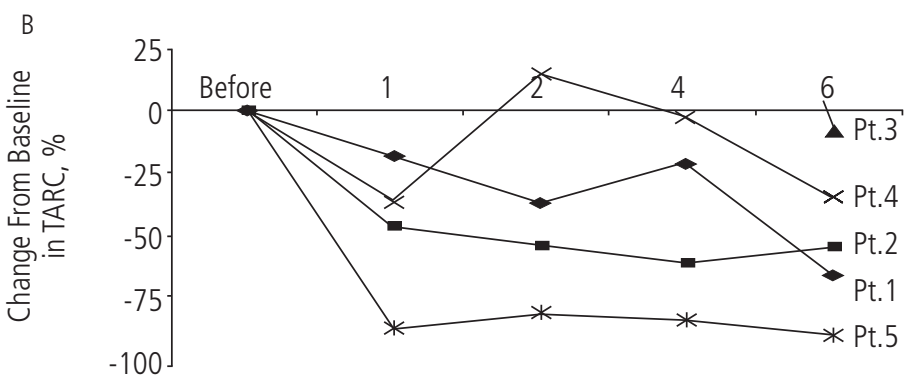

Months After Treatment

Figure. A, Change in the frequency of $\gamma \delta \mathrm{T}(\square+\mathbf{\square})$ and $V \gamma 9 \gamma \delta \mathrm{T}(\mathbf{\square})$ cells in AD patients receiving a single intravenous injection of zoledronate-activated $\gamma \delta \mathrm{T}$ cells. In Patients 2 and 5 , the frequencies of $V \gamma 9 \gamma \delta \mathrm{T}$ cells were maintained until 6 months after administration and increased 11.9- and 4.7-fold compared with before treatment, respectively. $B$, Change in the levels of the $T_{H} 2$ biomarkers TARC in AD patients who received a single intravenous injection of zoledronateactivated $\gamma \delta$ T cells. In the 2 patients whose AD severity index improved, the decreases in the levels of TARC 1 month after treatment were $46.2 \%$ and $87.7 \%$. TARC indicates thymus and activation-regulated chemokine.

thymus and activation-regulated chemokine (TARC) [8] and levels of $\operatorname{IgE}$ and eosinophils of each patient were also evaluated within 6 months of administration of zoledronateactivated $\gamma \delta$ T cells.

The number of injected zoledronate-activated $\gamma \delta \mathrm{T}$ cells ranged from 5.0 to $9.5 \times 10^{9}$. No adverse events were observed during the 6 months after administration. The evaluation of clinical outcome revealed that the clinical index of AD severity improved in 2 of the 5 patients (Patient 2, 7 to 1; Patient 5, 10 to 4 ). In 1 patient (Patient 1 ), the clinical index returned to the initial level of the evaluation after a transient improvement; however, no improvement in atopic dermatitis was observed for 2 patients (Patients 3 and 4). Flow cytometry of immune cells in peripheral blood before treatment revealed that the frequencies of $\gamma \delta \mathrm{T}$ and $\mathrm{V} \gamma 9 \gamma \delta \mathrm{T}$ cells ranged from $1.2 \%$ to $3.5 \%$ and from $0.3 \%$ to $2.5 \%$ of PBMCs, respectively. The change in the frequency of $\gamma \delta \mathrm{T}$ and $\mathrm{V} \gamma 9 \gamma \delta \mathrm{T}$ cells in PBMCs is shown in the Figure (Panel A). In the 2 patients whose AD severity index improved, the frequencies of both $\gamma \delta \mathrm{T}$ and $\mathrm{V} \gamma 9 \gamma \delta \mathrm{T}$ cells increased markedly and were maintained until 6 months after administration. At this point, the frequencies of $\mathrm{V} \gamma 9 \gamma \delta \mathrm{T}$ cells in Patients 2 and 5 increased to 11.9- and 4.7-fold compared with before treatment, respectively. In Patient 3 (no clinical improvement), the frequency of $\mathrm{V} \gamma 9 \gamma \delta \mathrm{T}$ cells increased transiently after administration but decreased promptly after 2 months of treatment. Flow cytometry also demonstrated that the frequency of $\mathrm{T}_{\mathrm{H}} 2$ cells decreased in 2 patients, with an improvement in the clinical index of AD severity (Patient 2, 1.4 to 0.9 ; Patient, 5, 7.4 to 4.4), although no decrease was observed for the other 3 patients (data not shown). There were no significant changes in the frequencies of $\mathrm{T}_{\mathrm{H}} 1$ cells, $\mathrm{B}$ cells, or Tregs after administration of zoledronate-activated $\gamma \delta \mathrm{T}$ cells in any of the 5 patients. The assessment of $\mathrm{T}_{\mathrm{H}} 2$ biomarker levels demonstrated that the mean percentage change in TARC levels in Patients 1, 2, and 5 was $-35.9 \%,-54.1 \%$, and $-85.9 \%$, respectively, after treatment (Figure, Panel B). However, in Patient 3 (no clinical improvement), TARC levels at 1, 2, 4, and 6 months after the injection were $237.8 \%, 56.6 \%, 159.2 \%$, and $-7.6 \%$, respectively. In Patients 2 and 5, eosinophil counts fell below half after a month of treatment (data not shown). There was no notable decrease in IgE levels in any of the patients. This is the first study of zoledronate-activated $\gamma \delta$ T cell therapy for $\mathrm{AD}$ patients, in whom therapy was shown to be safe and feasible. In the 2 patients whose clinical index of AD severity improved, we observed a decrease in $\mathrm{T}_{\mathrm{H}} 2$ cell frequency, a decrease in TARC levels, and a 5 to $10-$ fold increase in the frequencies of $\mathrm{V} \gamma 9 \gamma \delta \mathrm{T}$ cells in PBMCs compared with before treatment. These data suggest that it is necessary to suppress $\mathrm{T}_{\mathrm{H}}$ 2-skewed immunity to markedly increase the $\mathrm{T}_{\mathrm{H}} 1$-polarized $\mathrm{V} \gamma 9 \gamma \delta \mathrm{T}$ cell frequency in PBMCs in AD patients. However, zoledronate-activated $\gamma \delta \mathrm{T}$ cells were not effective for AD patients with $\mathrm{T}_{\mathrm{H}} 1$-skewed immunity caused by a bacterial infection [9]. In treatment of cancer patients, more than 3 infusions of zoledronate-activated $\gamma \delta \mathrm{T}$ cells significantly 
increased the numbers of $\mathrm{V} \gamma 9 \gamma \delta \mathrm{T}$ cells $[3,4]$. Therefore, in future clinical trials, at least 3 injections of zoledronateactivated $\gamma \delta \mathrm{T}$ cells should be administered to engraft a large number of $\mathrm{V} \gamma 9 \gamma \delta \mathrm{T}$ cells in PBMCs. The effect of zoledronateactivated $\gamma \delta \mathrm{T}$ cells for AD patients should be evaluated in randomized controlled trials.

\section{Funding}

The authors declare that no funding was received for the present study.

\section{Conflicts of Interest}

The authors declare that they have no conflicts of interest.

\section{References}

1. Beck LA, Thaçi $D$, Hamilton JD, Graham NM, Bieber T, Rocklin $R$, Ming JE, Ren $H$, Kao R, Simpson E, Ardeleanu M, Weinstein SP, Pirozzi G, Guttman-Yassky E, Suárez-Fariñas M, Hager MD, Stahl N, Yancopoulos GD, Radin AR. Dupilumab treatment in adults with moderate-to-severe atopic dermatitis. N Engl J Med. 2014;371:130-9.

2 Otsuka A, Doi H, Egawa G, Maekawa A, Fujita T, Nakamizo S, Nakashima C, Nakajima S, Watanabe T, Miyachi Y, Narumiya S, Kabashima K Possible new therapeutic strategy to regulate atopic dermatitis through upregulating filaggrin expression. J Allergy Clin Immunol. 2014;133:139-46.

3 Noguchi A, Kaneko T, Kamigaki T, Fujimoto K, Ozawa M, Saito M, Ariyoshi N, Goto S. Zoledronate-activated $V \gamma 9 \gamma \delta$ T-cellbased immunotherapy is feasible and restores the impairment of $\gamma \delta$ T-cells in patients with solid tumors. Cytotherapy. 2011;13:92-7.

4 Abe $Y$, Muto M, Nieda M, Nakagawa Y, Nicol A, Kaneko T, Goto S, Yokokawa K, Suzuki K. Clinical and immunological evaluation of zoledronate-activated Vgamma9gammadelta T-cell-based immunotherapy for patients with multiple myeloma. Exp Hematol. 2009;37:956-68.

5 Böhm L, Maxeiner J, Meyer-Martin H, Reuter S, Finotto S, Klein M, Schild H, Schmitt E, Bopp T, Taube C. IL-10 and regulatory $\mathrm{T}$ cells cooperate in allergen-specific immunotherapy to ameliorate allergic asthma. J Immunol. 2015;194:887-97.

6 Kim HS, Yun JW, Shin TH, Lee SH, Lee BC, Yu KR, Seo Y, Lee S, Kang TW, Choi SW, Seo KW, Kang KS. Human umbilical cord blood mesenchymal stem cell-derived PGE2 and TGF- $\beta 1$ alleviate atopic dermatitis by reducing mast cell degranulation. Stem Cells. 2015;33:1254-66.

7 Saeki H, Furue M, Furukawa F, Hide M, Ohtsuki M, Katayama I, Sasaki R, Suto H, Takehara K; Committee for guidelines for the management of atopic dermatitis of Japanese Dermatological Association. Guidelines for management of atopic dermatitis. J Dermatol. 2009;36:563-77.

8 Kakinuma T, Nakamura K, Wakugawa M, Mitsui H, Tada Y, Saeki H, Torii H, Asahina A, Onai N, Matsushima K, Tamaki $K$. Thymus and activation-regulated chemokine in atopic dermatitis: Serum thymus and activation-regulated chemokine level is closely related with disease activity. J Allergy Clin Immunol. 2001;107:535-41.
9 Kasraie S, Niebuhr M, Kopfnagel V, Dittrich-Breiholz O, Kracht M, Werfel T. Macrophages from patients with atopic dermatitis show a reduced CXCL10 expression in response to staphylococcal $\alpha$-toxin. Allergy. 2012;67:41-9.

- Manuscript received May 16, 2016; accepted for publication June 20, 2016.

Takashi Kamigaki Center for Clinical Trials and Research Seta Clinic, 2-1-45 Kanda-surugadai, Chiyoda, Tokyo Japan

Zip code: 1010062 E-mail: kamigaki@j-immunother.com 


\section{Evaluation of Tolerance in Patients With Type-1 Hypersensitivity Reaction to Wheat After Oral Immunotherapy}

Khalili $\mathrm{A}^{1}$, Khayatzadeh $\mathrm{A}^{2}$, Ebrahimi $\mathrm{M}^{2}$, Rafiemanesh $\mathrm{H}^{3}$, Azizi $\mathrm{G}^{4,5}$, Movahedi $\mathrm{M}^{2}$

${ }^{\prime}$ Department of Pediatrics, Shahid Sadoughi University of Medical Sciences, Yazd, Iran

${ }^{2}$ Department of Allergy and Clinical Immunology, Children's Medical Center, Tehran University of Medical Sciences, Tehran, Iran ${ }^{3}$ Department of Epidemiology, School of Public Health, Shahid Beheshti University of Medical Sciences, Tehran, Iran ${ }^{4}$ Department of Laboratory Medicine, Imam Hassan Mojtaba Hospital, Alborz University of Medical Sciences, Karaj, Iran ${ }^{5}$ Research Center for Immunodeficiencies, Pediatrics Center of Excellence, Children's Medical Center, Tehran University of Medical Sciences, Tehran, Iran

J Investig Allergol Clin Immunol 2016; Vol. 26(5): 339-340 doi: 10.18176/jiaci.0093

Key words: Tolerance. Type 1 hypersensitivity. Immunotherapy.

Palabras clave: Tolerancia. Hipersensibilidad tipo 1. Inmunoterapia.

Adverse food reactions are unwanted reactions after ingestion of foods or food additives. The prevalence of wheat allergy is $0.2 \%-0.9 \%$ in adults and $0.4 \%-1.3 \%$ in children $[1,2]$. IgE-mediated reactions usually begin with acute symptoms within 2 hours after exposure to food [3-6]. In this study, we evaluate the development of tolerance in wheatallergic patients who had been desensitized according to a known protocol. In our previous study, 13 patients with wheat allergy completed 1 year of follow-up after the maintenance phase of an immunotherapy protocol. These patients were desensitized based on a previously reported protocol [7]. Ten of the 13 patients were aged $>5$ years. At the time, oral food challenge (OFC) was performed with Senan bread containing $10 \%$ protein after a 2 -week wheat-free diet. The OFC was performed at intervals of 15 minutes with doses of $0.8,0.8$, 1.6, 3.2, 6.4, 13.5, 26, and $52 \mathrm{~g}$ of sliced bread (Senan). The cutoff for clinical tolerance was $52 \mathrm{~g}$ of bread. Patients were tested with skin prick test extract (Greer), and the size of the wheal was compared before and after the desensitization period. Moreover, serum-specific IgE was measured using the RIDA qLine Allergy Panel (R-Biopharm) and compared before and after desensitization. Statistical analyses were performed using IBM SPSS Statistics for Windows, Version 20.0 (IBM Corp). The Fisher exact and chi-square tests were used to compare categorical variables; the Pearson and Spearman rank correlation tests were used to assess the correlation between variables. Mean age was 9.1 years (range, 6-20 years). Two of the 10 patients were females and the rest were males. Patients were divided into 2 groups according to their primary presentations (anaphylaxis or no anaphylaxis). Eight patients had anaphylaxis before desensitization. The allergic manifestations before immunotherapy affected the skin, respiratory tract, and gastrointestinal tract (Table). During desensitization, patients were evaluated for complaints. Seven

Table. Frequency of Symptoms and Complaints Before and During Treatment

Variable

Primary symptoms of anaphylaxis

Symptoms before immunotherapy

Symptoms during the wheat-containing diet

Symptoms during the 1-year immunotherapy period

Symptoms during the open food challenge

\begin{tabular}{|c|c|}
\hline & Frequency, No (\%) \\
\hline Yes & $8(80)$ \\
\hline No & $2(20)$ \\
\hline Facial angioedema & $1(10)$ \\
\hline Urticaria & $9(90)$ \\
\hline Wheezing and shortness of breath & $7(70)$ \\
\hline Rhinorrhea, pruritus, and nasal congestion & $2(20)$ \\
\hline Vomiting and stomach cramps & $1(10)$ \\
\hline Type 1 symptoms (occasionally) ${ }^{\mathrm{a}}$ & $7(70)$ \\
\hline Initial symptoms ${ }^{\mathrm{b}}$ & $3(30)$ \\
\hline Urticaria & $4(40)$ \\
\hline Wheezing and dyspnea & $2(20)$ \\
\hline Rhinorrhea & $1(10)$ \\
\hline Generalized pruritus & $1(10)$ \\
\hline Chronic constipation & $1(10)$ \\
\hline Bloating and chronic abdominal distention & $1(10)$ \\
\hline Urticaria & $4(40)$ \\
\hline Ocular pruritus & $2(20)$ \\
\hline Rhinorrhea & $3(30)$ \\
\hline Dyspnea and wheezing & $0(0)$ \\
\hline Gastrointestinal symptoms & $0(0)$ \\
\hline
\end{tabular}

aHives, wheezing, rhinorrhea, and pruritus.

${ }^{\mathrm{b}}$ Chronic constipation, abdominal bloating, and distension. 
patients occasionally had type 1 allergic signs and symptoms. However, clinical manifestations were not as severe as the primary presentations before the desensitization period. The allergic symptoms were urticaria, wheezing, rhinorrhea, and pruritus. A 6-year-old boy experienced chronic constipation when he ate wheat. This symptom may have been related to his wheat-containing diet, although constipation was ruled out by a gastroenterologist. A 9-year-old boy complained of abdominal distention and flatulence after following a wheat-containing diet. Anaphylactic reactions were recorded in 2 patients who did not develop tolerance. The reactions occurred after intake of $12 \mathrm{~g}$ and $13 \mathrm{~g}$ of bread. In other patients, allergic reactions were less severe and occurred at doses $>26$ g. In summary, out of the 10 patients evaluated, 4 tolerated $52 \mathrm{~g}$ of bread, and 6 patients experienced allergic reactions at doses of 12, 13, 26, 26, 26, and $52 \mathrm{~g}$. Among patients who had an anaphylactic reaction in the initial presentation, 3 developed clinical tolerance. Nevertheless, no significant correlation was found between tolerance and anaphylaxis $(P=.747)$ or between sex and age and development of tolerance ( $P=.747$ and $P=.920$, respectively). No significant correlation was found between sex and complications during the desensitization period $(P=.745)$. The mean wheal size before and after immunotherapy was $8.7 \mathrm{~mm}$ and $5.7 \mathrm{~mm}$, respectively $(P<.001)$. Mean specific $\mathrm{IgE}$ before and after desensitization was $53.92 \mathrm{IU} / \mathrm{mL}$ and $19.06 \mathrm{IU} / \mathrm{mL}$, respectively $(P<.001)$. Staden et al [8] showed that tolerance was achieved in $36 \%$ of milk- or egg-allergic patients who received oral immunotherapy for 21 months and then followed an elimination diet for 2 months. Allergenspecific IgE also decreased in the immunotherapy group. In 2003, Nucera et al [9] desensitized a 7-year-old girl with wheat allergy. After a 6-month treatment, skin prick tests were performed and specific IgE was determined, and no significant change was observed. Burks et al [10] administered oral egg immunotherapy to 55 egg-allergic patients after 12 months of immunotherapy, and the patients followed an elimination diet for 4-6 weeks. In the oral rechallenge, $28 \%$ of patients were tolerant [10]. In our study, we eliminated wheat from the patients' diet for 2 weeks in order to respect the duration of immunotherapy. After this period, tolerance was observed in $40 \%$ of the patients after the OFC. Although other patients did not achieve tolerance, the incidence of reactions prevented us from administering higher doses.

\section{Funding}

The authors declare that no funding was received for the present study.

\section{Conflicts of Interest}

The authors declare that they have no conflicts of interest.

\section{References}

1. Morita E, Chinuki Y, Takahashi H, Nabika T, Yamasaki M, Shiwaku K. Prevalence of wheat allergy in Japanese adults. Allergol Int. 2012;61(1):101-5.
2. Faber M, Van Gasse A, Sabato V, Hagendorens MM, Bridts $\mathrm{CH}$ De Clerck LS, Ebo DG. Marihuana allergy: beyond the joint. J Investig Allergol Clin Immunol. 2015;25(1):70-2.

3. Sutton R, Hill DJ, Baldo BA, Wrigley CW. Immunoglobulin E antibodies to ingested cereal flour components: studies with sera from subjects with asthma and eczema. Clin Allergy. 1982;12(1):63-74.

4. Ibanez MD, Escudero C, Sanchez-Garcia S, Rodriguez del Rio P. Comprehensive Review of Current Knowledge on Egg Oral Immunotherapy. J Investig Allergol Clin Immunol. 2015;25(5):316-28.

5. Lopez-Matas MA, Larramendi $\mathrm{CH}$, Huertas AJ, Ferrer $\mathrm{A}$, Moya R, Pagan JA, Navarro LA, Garcia-Abujeta JL, Carnes J. Tomato nsLTP as an "In Vivo" Diagnostic Tool: Sensitization in a Mediterranean Population. J Investig Allergol Clin Immunol. 2015;25(3):196-204.

6. Rodriguez del Rio P, Diaz-Perales $A$, Sanchez-Garcia $S$, Escudero $C$, do Santos $P$, Catarino M, Ibanez MD. Oral immunotherapy in children with IgE-mediated wheat allergy: outcome and molecular changes. J Investig Allergol Clin Immunol 2014;24(4):240-8.

7. Sato $S$, Utsunomiya T, Imai T, Yanagida N, Asaumi T, Ogura K, Koike Y, Hayashi N, Okada Y, Shukuya A, Ebisawa M. Wheat oral immunotherapy for wheat-induced anaphylaxis. J Allergy Clin Immunol. 2015;136(4):1131-3 e7.

8. Staden $U$, Rolinck-Werninghaus $C$, Brewe $F$, Wahn $U$, Niggemann B, Beyer K. Specific oral tolerance induction in food allergy in children: efficacy and clinical patterns of reaction. Allergy.2007;62(11):1261-9.

9. Nucera E, Pollastrini E, De Pasquale T, Buonomo A, Roncallo C, Lombardo C, Sabato V, Gasbarrini G, Schiavino D, Patriarca G. New protocol for desensitization to wheat allergy in a single case. Dig Dis Sci.2005;50(9):1708-9.

10. Burks AW, Jones SM, Wood RA, Fleischer DM, Sicherer SH, Lindblad RW, Stablein D, Henning AK, Vickery BP, Liu AH, Scurlock AM, Shreffler WG, Plaut M, Sampson HA, Consortium of Food Allergy R. Oral immunotherapy for treatment of egg allergy in children. N Engl J Med. 2012;367(3):233-43.

Manuscript received May 9, 2016; accepted for publication June 21, 2016.

Masoud Movahedi Department of Allergy and Clinical Immunology Children's Medical Center Tehran University of Medical Sciences Tehran, Iran E-mail: movahedm@sina.tums.ac.ir 


\section{Induction of Tolerance by Oral Immunotherapy in Patients With Cow's Milk Allergy}

Ebrahimi $\mathrm{M}^{1}$, Gharagozlou $\mathrm{M}^{1}$, Khalili $\mathrm{A}^{2}$, Magaji Hamid $\mathrm{K}^{3,4}$, Azizi $\mathrm{G}^{5,6}$, Movahedi $\mathrm{M}^{1}$

${ }^{1}$ Department of Allergy and Clinical Immunology, Children's Medical Center, Tehran University of Medical Sciences, Tehran, Iran

${ }^{2}$ Department of Pediatrics, Shahid Sadoughi University of medical sciences, Yazd, Iran

${ }^{3}$ Department of Immunology, School of Public Health, Tehran University of Medical Sciences, International Campus, Tehran, Iran

${ }^{4}$ Immunology Department, Faculty of Medical Laboratory Sciences, Usmanu Danfodiyo University Sokoto, Nigeria

${ }^{5}$ Department of Laboratory Medicine, Imam Hassan Mojtaba Hospital, Alborz University of Medical Sciences, Karaj, Iran

${ }^{6}$ Research Center for Immunodeficiencies, Pediatrics Center of Excellence, Children's Medical Center, Tehran University of Medical Sciences, Tehran, Iran

J Investig Allergol Clin Immunol 2016; Vol. 26(5): 341-343 doi: 10.18176/jiaci.0094

Key words: Immunotherapy. Desensitization. Cow's milk allergy. Tolerance.

Palabras clave: Inmunoterapia. Desensibilización. Alergia a leche de vaca. Tolerancia.

Cow's milk allergy is the most common type of food allergy [1]. In this study, we evaluated the efficacy of oral desensitization in the induction of tolerance in children aged $>3$ years with a history of cow's milk allergy. The inclusion criteria were a positive history of cow's milk allergy, positive skin prick test result, presence of specific IgE (sIgE) against whole cow's milk proteins or any isolated cow's milk protein, and a positive result in a double-blind, placebo-controlled food challenge (DBPCFC). The exclusion criteria were poor compliance, uncontrolled asthma, cardiovascular disease, and severe systemic disease. The Institutional Review Board approved the study, which was registered with the Iranian Clinical Trials Registry (Registration Code: IRCT2015041621793N1).

All of the patients underwent DBPCFC, in which the test meal consisted of a strawberry-flavored milk-based formula (BioMeal, Fassbel), and the placebo meal consisted of a strawberry-flavored soy-based formula (BioMeal Soy, Fassbel). Initially, 3 drops of the solution were placed in the lower labial fornix, and then oral doses of $0.5,2,5$, 20, 60, and $162.5 \mathrm{~mL}$ were given every 15 minutes. Oral immunotherapy was administered in 3 phases (rush, buildup, and maintenance) [2]. After desensitization, patients were followed for 1 year to monitor allergic reactions. The use of cow's milk and dairy products was prohibited for 1 month in patients who experienced less severe reactions, and an open food challenge (OFC) test was subsequently performed. If the $\mathrm{OFC}$ result was negative, the patient was considered to have developed tolerance; if it was positive, the patient was considered to be desensitized.

sIgE against casein and cow's milk protein was measured and a skin prick test (SPT) performed with cow's milk extract (Greer Laboratories). From February 2014 to September 2015, a total of 14 patients ( 10 male and 4 female) were confirmed to have cow's milk allergy and were enrolled in the final analysis.

The statistical analyses were performed using IBM SPSS Statistics for Windows, Version 20.0 (IBM Corp). The Fisher exact and chi-square tests were used to compare categorical variables, whereas the Pearson test and Spearman correlation coefficient were used to assess the correlation between quantitative and qualitative variables, respectively.

The median age of patients was 4.75 (3.5-7) years, and the median follow-up period before initiation of this study was 14 (6-23) months. Seven patients $(50.0 \%)$ had a history of atopic disease, and 8 children $(57.1 \%)$ had a history of adverse reaction to other foods including fish, egg, tree nuts, and peanut. The most common clinical manifestation during the DBPCFC was rhinoconjunctivitis (57.1\%). In the buildup phase, 1190 doses of cow's milk $(5859 \mathrm{~mL})$ were administered to 13 patients, who completed the buildup phase successfully, and allergic reactions were recorded in 24 doses $(2.0 \%)$. Details of allergic reactions are shown in the Table. In addition, patient 9 left the study during the sixth week of the buildup phase because of severe allergic reactions (Table). During the maintenance phase, 1170 doses of cow's milk $(261000 \mathrm{~mL})$ were administered and 11 allergic reactions $(0.9 \%)$ were recorded in 9 patients (patients 1 and 12 had 2 episodes each). The result of SPT showed that the median diameter of the wheal before and after desensitization was 10 and $6 \mathrm{~mm}$, respectively. Moreover, the sIgE level to cow's milk proteins and casein decreased after desensitization from 39.30 to $10.40 \mathrm{kU}_{\mathrm{A}} / \mathrm{L}$ and 7.72 to $2.83 \mathrm{kU}_{\mathrm{A}} / \mathrm{L}$, respectively. After oral immunotherapy, the result of the SPT and SIgE levels against casein and milk proteins decreased significantly ( $P=.002$ and .003 , respectively). Among 13 patients, the result of the OFC test was negative in 6 cases $(46.2 \%)$, and tolerance was considered relevant in 4 patients $(30.8 \%) ; 3$ patients $(23 \%)$ were unable to tolerate milk, and clinical symptoms developed after ingestion of $20 \mathrm{~mL}$ of milk. Age, sex, and previous medical history had no significant correlation with the results of the OFC test. Induction of tolerance was significantly more successful in patients with a higher reactive dose in the DBPCFC test and buildup phase, less severe reactions during the immunotherapy protocol, and a shorter duration of immunotherapy. In this study, most of the allergic reactions in the buildup and maintenance phases were mild and could be controlled with oral antihistamines. Short-acting B-agonists were administered to treat 15 allergic episodes in the build-up phase and 2 episodes in the maintenance phase. Moreover, 2 patients had to be treated with intramuscular epinephrine in the buildup phase ( 1 received 2 doses). Our results and the results of similar studies show that oral immunotherapy is a relatively safe approach if the necessary precautions are taken [3-5]. We found that the dose tolerated at the beginning of the study correlated with the development of tolerance at the final stage. Our results were similar to those of Staden et al [6] 
Table. Results of the Oral Immunotherapy Protocol

\begin{tabular}{|c|c|c|c|c|c|c|}
\hline $\begin{array}{l}\text { Patient } \\
\text { No. }\end{array}$ & $\begin{array}{l}\text { Buildup } \\
\text { Period, wk }\end{array}$ & $\begin{array}{l}\text { Dose of Allergic } \\
\text { Reaction, mL }\end{array}$ & $\begin{array}{c}\text { Allergic Reactions During } \\
\text { Buildup Phase }\end{array}$ & $\begin{array}{l}\text { Maintenance } \\
\text { Period, d }\end{array}$ & $\begin{array}{l}\text { Maintenance } \\
\text { Dose, } \mathrm{mL}\end{array}$ & $\begin{array}{c}\text { Allergic Reaction } \\
\text { (Maintenance Phase) }\end{array}$ \\
\hline \multirow[t]{2}{*}{1} & \multirow[t]{2}{*}{14} & 10 & Generalized urticaria $^{\mathrm{a}}$ & \multirow[t]{2}{*}{90} & \multirow[t]{2}{*}{200} & \multirow[t]{2}{*}{-} \\
\hline & & 60 & Localized urticaria, cough, wheezing ${ }^{\mathrm{b}}$ & & & \\
\hline 2 & 12 & 10 & Localized urticaria $^{\mathrm{a}}$ & 90 & 250 & $\begin{array}{l}\text { Localized urticaria, } \\
\text { rhinoconjunctivitis }^{\mathrm{a}, \mathrm{e}}\end{array}$ \\
\hline \multirow[t]{3}{*}{3} & \multirow[t]{3}{*}{18} & 2 & $\begin{array}{l}\text { Generalized urticaria, } \\
\text { cough, rhinoconjunctivitis }^{\text {b }}\end{array}$ & \multirow[t]{3}{*}{90} & \multirow[t]{3}{*}{200} & \multirow{3}{*}{$\begin{array}{l}\text { Cough, } \\
\text { rhinoconjunctivitis, } \\
\text { wheezing }^{\mathrm{b}}\end{array}$} \\
\hline & & 40 & $\begin{array}{l}\text { Generalized urticaria, sneezing, } \\
\text { wheezing, rhinoconjunctivitis, } \\
\text { respiratory distress }{ }^{c}\end{array}$ & & & \\
\hline & & 100 & $\begin{array}{l}\text { Generalized urticaria, } \\
\text { rhinoconjunctivitis, sneezing }\end{array}$ & & & \\
\hline 4 & 10 & - & - & 90 & 250 & $\begin{array}{l}\text { Sneezing, } \\
\text { rhinoconjunctivitis }\end{array}$ \\
\hline \multirow[t]{3}{*}{5} & \multirow[t]{3}{*}{18} & 10 & $\begin{array}{l}\text { Generalized urticaria, } \\
\text { cough, wheezing }\end{array}$ & \multirow[t]{3}{*}{90} & \multirow[t]{3}{*}{200} & \multirow[t]{3}{*}{$\begin{array}{l}\text { Localized urticaria, } \\
\text { throat pruritus }\end{array}$} \\
\hline & & 40 & $\begin{array}{l}\text { Generalized urticaria, } \\
\text { cough, rhinoconjunctivitis }\end{array}$ & & & \\
\hline & & 100 & $\begin{array}{l}\text { Generalized urticaria, } \\
\text { cough, rhinoconjunctivitis }\end{array}$ & & & \\
\hline 6 & 10 & 40 & $\begin{array}{l}\text { Generalized urticaria, sneezing, } \\
\text { rhinoconjunctivitis }{ }^{\mathrm{a}}\end{array}$ & 90 & 250 & $\begin{array}{l}\text { Localized urticaria, } \\
\text { rhinoconjunctivitis }^{\mathrm{a}}\end{array}$ \\
\hline 7 & 10 & - & - & 90 & 250 & - \\
\hline \multirow[t]{2}{*}{8} & \multirow[t]{2}{*}{12} & 40 & Generalized urticaria, cough ${ }^{\mathrm{b}}$ & \multirow[t]{2}{*}{90} & \multirow[t]{2}{*}{250} & \multirow[t]{2}{*}{ Localized urticaria $^{\mathrm{a}}$} \\
\hline & & 150 & Localized urticaria, cough ${ }^{\mathrm{b}}$ & & & \\
\hline 9 & 10 & 10 & Vomiting, abdominal pain & - & - & - \\
\hline \multirow[t]{3}{*}{10} & \multirow[t]{3}{*}{15} & 10 & Cough, wheezing ${ }^{\mathrm{b}}$ & \multirow[t]{3}{*}{90} & \multirow[t]{3}{*}{200} & \multirow{3}{*}{$\begin{array}{l}\text { Sneezing, } \\
\text { rhinoconjunctivitis }^{\mathrm{a}}\end{array}$} \\
\hline & & 100 & Cough, rhinoconjunctivitis ${ }^{b}$ & & & \\
\hline & & 5 & Sneezing, rhinoconjunctivitis ${ }^{\mathrm{a}}$ & & & \\
\hline \multirow[t]{3}{*}{11} & \multirow[t]{3}{*}{11} & 5 & Generalized urticaria, cough ${ }^{\mathrm{b}}$ & \multirow[t]{3}{*}{90} & \multirow[t]{3}{*}{200} & \multirow[t]{3}{*}{ Localized urticaria $^{\mathrm{a}}$} \\
\hline & & 20 & Generalized urticaria, cough ${ }^{\mathrm{b}}$ & & & \\
\hline & & 150 & $\begin{array}{l}\text { Localized urticaria, throat pruritus, } \\
\text { rhinoconjunctivitis }{ }^{\mathrm{a}}\end{array}$ & & & \\
\hline \multirow[t]{3}{*}{12} & \multirow[t]{3}{*}{20} & 5 & Cough, rhinoconjunctivitis, wheezing & 90 & 200 & Cough, \\
\hline & & 60 & Cough, rhinoconjunctivitis, wheezing ${ }^{\mathrm{b}}$ & & & rhinoconjunctivitis ${ }^{\mathrm{b}, \mathrm{e}}$ \\
\hline & & 100 & $\begin{array}{l}\text { Cough, rhinoconjunctivitis, } \\
\text { wheezing, flushing }\end{array}$ & & & \\
\hline 13 & 10 & 40 & Sneezing, rhinoconjunctivitis ${ }^{\mathrm{a}}$ & 90 & 200 & - \\
\hline & & 100 & $\begin{array}{l}\text { Sneezing, throat pruritus, } \\
\text { rhinoconjunctivitis }^{\mathrm{a}}\end{array}$ & & & \\
\hline 14 & 10 & 60 & Throat pruritus, rhinoconjunctivitis ${ }^{\mathrm{a}}$ & 90 & 250 & - \\
\hline
\end{tabular}

${ }^{a}$ Treatment with oral diphenhydramine.

${ }^{b}$ Treatment with oral diphenhydramine and a short-acting B-agonist.

'Treatment with oral diphenhydramine, a short-acting $\beta$-agonist, and 2 doses of epinephrine and admission to hospital.

${ }^{\mathrm{d}}$ Treatment with oral diphenhydramine, a short-acting $\beta$-agonist, and a single dose of epinephrine.

'Two episodes of allergic reactions. 
and Longo et al [7]. Finally, based on the results obtained in this study and other studies [8-10], it could be concluded that oral immunotherapy leads to tolerance and may accelerate induction of tolerance in patients with cow's milk allergy.

\section{Funding}

The authors declare that no funding was received for the present study.

\section{Conflicts of Interest}

The authors declare that they have no conflicts of interest.

\section{References}

1. Martorell Calatayud C, Muriel Garcia A, Martorell Aragones A, De La Hoz Caballer B. Safety and efficacy profile and immunological changes associated with oral immunotherapy for IgE-mediated cow's milk allergy in children: systematic review and meta-analysis. J Investig Allergol Clin Immunol. 2014;24(5):298-307.

2. Zapatero L, Alonso E, Fuentes, V, Martinez Ml. Oral desensitization in children with cow's milk allergy. J Investig Allergol Clin Immunol. 2008;18(5):389-96.

3. Vila L, Garcia V. Oral tolerance induction with wheat: a valid therapeutic option in allergic patients. J Investig Allergol Clin Immunol. 2015;25(1):77-8.

4. Garcia-Ara C, Pedrosa M, Belver MT, Martin-Munoz MF, Quirce S, Boyano-Martinez, T. Efficacy and safety of oral desensitization in children with cow's milk allergy according to their serum specific IgE level. Ann Allergy Asthma Immunol. 2013;110(4): 290-4.
5. Meglio P, Bartone E, Plantamura M, Arabito E, Giampietro PG. A protocol for oral desensitization in children with IgEmediated cow's milk allergy. Allergy. 2004;59(9):980-7.

6. Staden $U$, Rolinck-Werninghaus $C$, Brewe $F$, Wahn $U$, Niggemann B, Beyer K. Specific oral tolerance induction in food allergy in children: efficacy and clinical patterns of reaction. Allergy. 2007;62(11):1261-9.

7. Longo G, Barbi E, Berti I, Meneghetti R, Pittalis A, Ronfani $\mathrm{L}$, Ventura $A$. Specific oral tolerance induction in children with very severe cow's milk-induced reactions. J Allergy Clin Immunol. 2008;121(2):343-7.

8. Demir S, Olgac M, Saglam S, Gelincik A, Colakoglu B, Buyukozturk S. Successful Capecitabine Desensitization for a Delayed-Type Hypersensitivity Reaction. J Investig Allergol Clin Immunol. 2016;26(1):66-7.

9. Ibanez MD, Escudero C, Sanchez-Garcia S, Rodriguez del Rio P. Comprehensive Review of Current Knowledge on Egg Oral Immunotherapy. J Investig Allergol Clin Immunol. 2015;25(5):316-28.

10. Rodriguez CG, Torrijos EG, De la Pinzon FR, Segade JB, Rodriguez RG, Brito FF, Rodriguez-Sanchez J. Dysphagia in a boy treated with oral immunotherapy for cow's milk allergy. J Investig Allergol Clin Immunol. 2014;24(5):363-5.

Manuscript received May 7, 2016; accepted for publication June 21, 2016.

Masoud Movahedi

E-mail: movahedm@sina.tums.ac.ir 